EstAg 29 (1994) 217-242

\title{
La mateana Tradición Histórica sobre las apariciones del Resucitado *
}

\author{
(Mt 28,9-10.16-20)
}

\author{
Análisis histórico-tradicional
}

Los cuatro evangelistas concluyeron y culminaron los respectivos evangelios con sus interpretados relatos anastasiológicos ${ }^{1}$.

Todos ellos valoraron pues la Resurrección de Jesús como piramidal cima de su ministerio mesiánico. Con éste enlazan efectivamente aquellos relatos pascuales no sólo por los reiterados vaticinios autoanastasiológicos ${ }^{2}$, también por la mención de «las mujeres» ${ }^{3}$, de «sus discípulos y Pedro» ${ }^{4}$ o de

* Sobre las Cristofanías pascuales de los cuatro relatos evangélicos, en general, cf. W.NAUCK, Die Bedeutung des leeres Grabes für den Glauben an den Auferstandenen: ZNW 47 (1956) 243-67; H. von CAMPENHAUSEN, Der Ablauf der Osterereignisse und das leere Grab, Heidelberg 21958, 20-54; C.M. MARTINI, Il problema storico della Risurrezione negli studi recenti, Roma 1959, 114-45; P. BENOIT, Marie-Madeleine et les Disciples au Tombeau de Jésus (BZNW 26), Fs. J. JeREMIAS (Hrsg.v.W.Eltester), Berlin 1960,141-62; ID., Passion et Résurrection, Paris 1966, 277-353; P. Benolt, Passion et résurrection du Seigneur, Paris, 1963, 277-344; G. Koch, Die auferstehung Jesu Christi (BHth 27), Tübingen ${ }^{2}$ 1965, 157-207; E. GuTTENBERG, Zur Geschichtlichkeit der Auferstehung Jesu: ZKth 88 (1986) 257-72; E. RUCKSTUHL-J. PFAMmATTER, Die Auferstehung Jesu Christi, Luzern-München 1968, 43-55.91-104; J. JEREMIAS, Neutestamentliche Theologie, Gütersloh 1971, 285-95 (trad.españ., 347-59); X. LÉON-Dufour, Résurrection de Jésus et message pascal, Paris 1971, 121-71 (trad. españ., 135-85); B. Rigaux, Dieu l'a ressuscité, Gembloux 1973, 278-307: 295ss; E. DHANIs, La résurrection de Jésus et l'histoire: «Resurrexit» (ed. E. Dhanis), Città del Vaticano 1974, 557-641:597-610; R. PESCH, Markus II 529-36.548-55; G. GnILKA, Markus II 345-47; Mathäus II 496-97.500=1.511s; J. SCHMITT, Résurrection de Jésus. DBS x 487-582:532-50; J. CABA, Resucitó Cristo, mi esperanza, Madrid 1986, 286-337 (más bibliografía en las páginas siguientes).

1. Cf. S. SABugal, Credo. La fe de la Iglesia, Zamora 1986, $602-28$ (bibliogr.); ID., La resurrección de Jesús en el evangelio de Mateo (Mt 28,1-20): Salesianum 53 (1991) 467-78; La resurrección de Jesús en el evangelio de Lucas (Lc 24,1-49): $\operatorname{Re} A g 33$ (1992) 463-94; La resurrección de Jesús en el cuarto Evangelio (Jn 20-1-29; 21,1-14): Salesianum 53 (1991) 649-67.

2. Mc 16,7=14,28; Mt 28,7=26,32; Lc 24,6=9,22.

3. Mc $16,1-15,47 ;$ Mt $28,1=27,61 ;$ Lc $24,1=23,55 \mathrm{~s}$.

4. Mc 16,7par $=14,26=52.66 .72$ par. 
«Pedro y el discípulo amado» 5 así como por los mismos nombres del Resucitado, identificado con el histórico «Jesús» ${ }^{6} \mathrm{o}$ «el crucificado Jesús» ${ }^{7}$ con «Jesús de Nazaret» o «el crucificado Jesús el Nazareno» y el «Maestro» ${ }^{8}$. Esto muestra ya, que los cuatro relatos evangélicos no pueden ser valorados «a priori» como creaciones literarias de los evangelistas: Estos debieron redactarlos sobre una tradición previa enraizada en el subsuelo de eventos sustancialmente tan históricos como los personajes mencionados ${ }^{9}$. Es lo que confirmará el siguiente análisis histórico-tradicional del relato mateano sobre las apariciones del Resucitado a las mujeres (Mt 28,9-10) y a «los once» discípulos (Mt 28,16-20) ${ }^{10}$ : Tras esforzarnos por delimitar a) su respectiva tradición evangélica, b) intentaremos detectar la raíz histórica de ambos eventos pascuales, no sin hodiernizar su mensaje anastasiológico.

"Y he aquí que Jesús les salió al encuentro, diciéndoles: ¡Alegraos! Ellas, acercándose, abrazaron sus pies y le adoraron (v.9). Entonces les dice Jesús: ¡No temáis! ¡Id, anunciad a mis hermanos que vayan a Galilea, y me verán (="ópsontai») allí! (v.10)... Pero los Once discípulos fueron a Galilea, al monte que les había ordenado Jesús (v.16); y viéndole (="idóntes») le adoraron, pero algunos dudaron (v.17). Y acercándose Jesús les habló, diciendo: Me fue dada toda potestad en el cielo y sobre la tierra (v. 18); id pues y haced discípulos a todas las naciones paganas, bautizándolas en el nombre del Padre y del Hijo y del

5. Jn $20,2-10=13,23-24 ; 18,15=16$.

6. Mc 16,9; Mt 28,9.16.18; Lc 24,15; Jn 20,12.14.16.17; 21,4.5.10.12.13.14.

7. Mt 28,5.

8. Lc 24,19; Mc16,6; Jn 20,16.

9. A este respecto, Cf. los estudios de: W. MichaELIS, Die Erscheinungen des Auferstandenen, Bazel 1994, 14-22.43-78; ID., Oráo: ThWNT V 340-68:355-60; W. NAUCK, a.c. (ZNW 1956), 258s; H. von Campenhausen, Ablauf, 42-52; C.M.Martini, Il Problema, 126-38; CH. H. DodD, Historical tradition in the Fourth Gospel, Cambridge 1963, 142-50 (trad. españ. 150-57); X. LÉON-Dufour, Les Évangiles, $446-49$ (trad. españ., 391-93); ID., Résurrection, 271-76 (trad. españ., 285-91); H. Grass, Ostergeschehen, 15-93: 85ss; P. BENoIT, Passion et Résurrection, 3074; CH. H. DoDD, The appareances ot the Risen Christ: «More New Testament Studies, London 1963, 102-33; G. KocK, Auferstehung, 171-207; K. H. RENGSTORF, Die Auferstehung Jesu, Witten 21967, 48-62.74-91; H. SCHLIER, Auferstehung, 30-39; E. RuCKSTUHL, Auferstehung 92-104; A. George, Les récits d'apparitions aux Once à partir de Lc 24,36-53: «La résurrection de Jésus et l'exégèse moderne» (LD 50), París 1969, 75-104; J. JEREMIAS, Theologie NT, 290-92 (trad. españ., 353-56); B. Rigaux, Dieu l'a réssuscité 281-88.297-99; E. DHanis, e.c. (en «Resurrexit») 601-10; J.E. Alsup, The Post-Resurrection-Appearences stories of the Gospel tradition. A storyof-tradition analysis with texts-synopsis (CthM 5), Stuttgart 1975; J. KREMER, Osterevangelien 74-76.90-91.130-32.151-52.178-80. 198-99.224; J. SCHMITT, a.c. (DBS, x) 537-50; J. CABA, Resucitó, 311-37 (más bibliografía en las páginas siguientes).

10. Cf. E. Lohmeyer-W. Schmauch, Matthäus 407,9; CH. H. Dodd, e.c., 105-7; X. LÉONDufour, Résurrection, 126-27.137-44 (trad.españ., 140-41.150-57); J. LANGE, Das Erscheinen des Auferstandenen nach Matthläusevangelium (FzB 11), Würzburg 1973; J. KREMER, Osterevangelien 74-76.90s; J. GNILKA, Matthäus II 496, 504-5.511 (más bibliografía en las notas siguientes). 
Espíritu Santo (v. 19, enseñándoles a observar cuanto os mandé. Y he aquí que yo estoy con vosotros todos los días, hasta el fin del mundo" (v. 20).

El relato anastasiofánico de Mt comprende pues la Cristofanía a las mujeres junto al Sepulcro de Jesús (vi. 9-10), y a los "los Once" en "el monte" de "Galilea" (v. 16-20). Orillados los datos característicos-vocabulario y estilo- de la redacción mateana ${ }^{1}$, ¿late tras ésta una tradición previa? Y, en caso afirmativo, ¿contiene datos sustancialmente históricos la tradición usada por $\mathrm{Mt}$ ?

\section{1) LA CRISTOFANIA A LAS MUJERES}

(Mt 28,9-10)

Mateo es el primer evangelista, que nos informa sobre la aparición del Resucitado a las mujeres ${ }^{2}$. Ese es su mérito. Un relato, por lo demás, muy breve. Y estrechamente ligado al previo sobre el Sepulcro vacío (Mt 28,1-8), por varios indicios literarios. El reiterado uso del nombre «Jesús» (vv. 5 . 9.10) así como la evocación pronominal («ellas»: vv. 9.10) de las mencionadas mujeres (v.1). ¿Trasluce su redacción literaria el uso de una tradición anastasiofánica basilarmente histórica?

\section{A. La pascua tradición evangélica}

Detectar la hipotética tradición usada por el Evangelista exige un detallado análisis del texto mateano, que precise los datos redaccionales y detecte los que son ajenos a su redacción literaria. Ahora bien, Mateo redactó el v. 9 no sólo introduciéndolo con la expresión «y he aquí», ${ }^{3}$ también añadien-

1. Cf. J. C. Hawkins, Horae synopticae, Oxford ${ }^{6}$ 1909, 3-10-35.154-73; M. J. LAGRANGE, Matthieu, LXXI-CVII; U. LuZ, Matthäus I 31-56; W. SCHENK, Die Sprache des Matthäus, Göttingen 1987.

2. Para su análisis tradicional, Cf.: J. LEAL, Mateo y la aparición de Cristo a la Magdalena: EstB 7(1948) 5-28: 955; E. LOHMEYER-W. SCHMAUCH, Matthäus 407-9; CH.H. DoDD, e.c., 105-7; X. LÉon-DOFOuR, Résurrection, 126s (trad. españ. 140s); J. LANGE, o.c., 370-85; J. KREMER, Osterevangelien 74-76; J. GNILKA, Matthäus II 495s.

3. El uso de «kai idoú» es ligeramente característico de Mt (=Mc 0,Mt 27, Lc $24=$ Act 11), quien la usa frecuentemente en el contexto de relatos epifánicos (Mt 2,9; 3,16.17; 4,11; 8,24.29; 17,3-5), como en su relato anastasiofánico lo hace (Mt 28, 2.7.9), repitiendo lo prevamente usado (vv. 7-9) por ser «repetitivo, su estilo» ((Cf. infra, n. 6). Así con: J. LANGE, o.c., 328; W. SCHENK, o.c., 297s. Sobre su uso en Mt 28, 20; Cf; infra, n. 25. 
do el part. «acercándose» ${ }^{4}$ así como la expresión «y le adoraron» ${ }^{5}$. Los demás vocablos no son propios de Mt y, por tanto, ésta sería la tradición por él usada: «Jesús les salió al encuentro ${ }^{6}$, diciendo: ¡Salve! ${ }^{7}$ y ellas abrazaron sus pies» ${ }^{8}$. A la redacción mateana del v. 10 pertenecen el adv. «entonces»y el nombre «Jesús» ${ }^{9}$, así como la orden del Resucitado «que vaya a Galilea y allí me verán» ${ }^{10}$. Los restantes vocablos no acusan la redacción de $\mathrm{Mt}$ y, por tanto, ésta sería la tradición pre-mateana: «y les dice. ¡No temáis! ${ }^{11}$. ¡Id,

4. Característico del vocabulario mateano es tanto el verbo «prosérchesthai» (=Mc 5 , Mt 52 , Lc $10=$ Act 10$)$, como el part. "proselthoúsai» y análogos (=Mc 5, Mt 28, Lc 5). Así con J.LANGE, o.c., 370.

5. El uso del verbo «proskynéin» (=Mc 2, Mt 13, Lc $2=$ Act 11) es propio de Mt: Cg. J. C. Hoskyns, o.c., 7; M. M. J. LAGRAGE, o.c., CV11s. J. LANGE, o.c., 370s; W. SCHENK, o.c., 421s.

6. Parco uso del verbo «hypantáo» (Mc 1, Mt 2, Lc 2+Act 1), de cuyos dos textos mateanos (Mt 8,28; 28,9) sólo en este último tiene por sujeto a Jesús. Por lo demás, el pron. «autáis» se refiere sin duda a las mencionadas «María la Magdalena y la otra María» (Mt 28, 1), cuyos no repetidos nombres (v.9) es tradicional, pues «repetitivo es el estilo de Mateo»: U. LUZ, o.c., 31.

7. No es característico de Mt el verbo «chaíro» (=Mc 2, Mt 6, Lc $12+$ Act 7), cuyo saludo «chaírete» (=Mc 1, Mt 3, Lc 1+Act 2) difícilmente lo puso en labios de Jesús el mismo Evangelista (Mt 28,9) que, previamente, lo usó en labios del traidor Judas (Mt 26,49) y de los burladores soldados romanos (Mt 27,29 par). Aquel saludo griego (Cf. W. BAUER, Wörterbuch NT 1782, n. 2; H. CoNZELMANN, ThWnt IX $351 \mathrm{y}$, por tanto, normal entre los soldados romanos (Cf. Jn 19,3; Mt 27,29 par), proviene de la tradición cristiana (Cf. 2Jn 10-11): Contra J. LANGE, o.c., 370 .

8. El uso del verbo «kratéin» (=Mc 15 , Mt 12, Lc 2) no es característico de Mt, cuyo empleo en los textos relacionados con Jesús significa casi siempre «arrestar» y casi todos aquellos provienen de su fuente marcana (Mt 21,46 [=Mc 12;12]; 26,4.48.50.55=Mc 14,1.44.46.49) Es pues tradicional la expresión «abrazaron sus pies» (Mt 28,9; Cf. Jun 20,17), única en el NT: Contra J. LANGE, o.c, 373.

9. Si el adv. «tóte» es característico de Mt (=Mc 6, Mt 90, Lc $15+$ Act 21: Cf. J. C. Hoskyns, o.c., 8; M.-J.LAGRANGE, o.c., CIXs; U. LUZ, o.c, 52; W. SCHENK, o.c., 446), la repetición del nombre «Jesús» (v.9) es también redacción del Evangelista, cuyo «estilo es repetitivo». U. LUZ, o.c., 31.

10. El uso del verbo «apérchesthai» es caractrístico de Mt (=Mc 23, Mt 35, Lc 13+Act 3). También la repetición de la frase «a Galilea y allí me verán» (Cf. v.7) es mateana: Responde a «estilo repetitivo» de Mt (Cf. supra, n.9), cuyo preanuncio anastasiofánico «en Galilea» (v.7) reproduce literalmente al respectivo de la redacción marcana (Mc 16,7). Añadamos a este respecto, que Mt acusa una cierta preferencia por la mención de «Galilea» (Mc 12, Mt 16, Lc 13, Jn 17): En la «Galilea de los paganos» inició Jesús su ministerio mesiánico (Mt 4,12-16. vv. 12.15), «de Galilea» partió Jesús para iniciar su ministerio en «Judea» (Mt 19,1) y lo culmina con su resurrección (Mt 28,1-10), pero en «Gali» finaliza sus apariciones el Resucitado e inicia la misión universal de la Iglesia (Mt 28,16-20) post pascual Cf. supra, 000; infra, 000, n.3 (bibliogr.).

11. El presente histórico «légei» es característico de Mc, no de Mt (Cf. J. C. Hawkins, o.c., 144-49); pre-mateano es asimismo el pron. «autais» (Cf. supra, n. 6) así como el imperativo tranquilizante «me phobeisthe» (Mt 14,27 [=Mc 6,50; Jn 6,20]; 17,7; 28,5.10; Lc 2,10; 12,7), expresión frecuente en labios de Jesús (Mc 6,50 par; Mt 10,26.28.31 [=Lc 12,28]; 17,7; Cf. Mc 5,36; Lc 5,10; $12,7.32$ ) y además semítica (Cf. supra, 000, n.16). Su uso en labios del Resucitado es, pues, probablemente tradicional: contra J. LANGE, o.c., 377. 
anunciad ${ }^{12}$ a mis hermanos ${ }^{13}$ que me verán!» ${ }^{14}$. Los datos seguros logrados mediante indicios objetivos del precedente análisis literario, muestran con suficiente claridad que el relato de Mateo sobre la Cristofanía pascual a las mujeres no es creación de la literaria redacción mateana ${ }^{15}$. Ésta, por el contrario, fue elaborada por el Evangelista sobre «una tradición previa» ${ }^{16}$, cuyo texto sería:

«Jesús les salió al encuentro diciendo: ¡Alegráos! y ellas abrazaron sus pies (v.9). Y les dice: ¡No temáis! ¡Id, anunciad a mis hermanos, que me verán!» (v.10).

Esa tradición anastasiofánica es pues literariamente muy breve: Junto al sepulcro, el resucitado «Jesús salió al encuentro de» varias (¿cuántas?) mujeres; a cuyo saludo «jalegraos!» (=chairete), reaccionaron aquellas «abrazando sus pies»y, tras tranquilizarles - «no temáis!»- el Resucitado, les ordenó imperiosamente: «Id, anunciad a mis hermanos (=discípulos), que me verán!».

b) Una tradición sucinta, cuyo Mensaje anastasiológico contiene sin embargo datos importantes. Quien toma la iniciativa de manifestarse o «salir al encuentro» de las mujeres es «JESÚS»: El mesiánico «Jesús» histórico y previamente crucificado, con quien por tanto se identifica fundamentalmente el RESUCITADO corporalmente. Pues esa su corporaleidad anastásica refleja no sólo la promesa de "ser visto» por sus «hermanos» sino también su colo-

12. Los imperativos «hypágete, apangeílate» no son mateanos contra J. LANGE, o.c., 137 1s: En análogo contexto previo usó el Evangelista el similar mandato «poreúesthai eípate» (v.7); y lo habría reiterado aquí (v.10), dado que «repetitivo es su estilo»: Cf. supra, n.9.

13. Nombre de los «discípulos» (v.7), ligado en otro contexto mateano a una condición (Mt 12,49s; 25,40) y sólo aquí designados expresamente «hermanos» (J. GNILKA, Matthäus II 495) por el Jesús de Mato, quien los habría llamado «discípulos» (v.7), pues «repetitivo es su estilo» (Cf. supra, n. 9). La designación de aquéllos como «hermanos» de Jesús (v.10) es pues tradición cristiana (Cf. Rm 8,29; Hebr. 2,11), usada por Mt. Así con J. SCHNIEwIND, Das Evangelium des Matthäus (NTD 2), Göttingen 1964, 274; Cf. E. KLostermanN, Das Matthäusvangelium (HNT

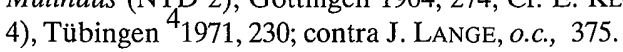

14. Esa sería la tradición pre-mateana: El uso de la conj. «que» (=hotí) no es característico de Mt (=Mc 110, Mt 141, Lc. 173, Jn 271), ni lo es su empleo para indicar el objeto del verbo siguiente (Cf. W. SCHENK, o.c, 378); tampoco el verbo «oráo» (=ver) caracteriza al vocabulario de $\mathrm{Mt}$ (=Mc 7, Mt 13, Lc 14, Jn 31), ni su uso con el significado anastasiológico de «ver» al Resucitado ó «ser manifestado» (=óphthe) éste (=Mc 1. Mt 3, Lc 3+Act 8, Jn 6, Ep. paul. 5).

15. Así con J. SCHMID, Matthäus 381 (trad. españ., 457). Contra J. LANGE (o.c., 370.383) y otros autores que, sin un previo análisis histórico-redaccional y tradicional del texto mateano, atribuyen los orígenes de éste a la redacción de Mt. F. NeIRYNCK, Les femmes au tombeau. 'Étude de la rédaction matteenne: NTS 15 (1968-69) 168-90: 181-84; J. KREMER, Osterevangelien, 74,76 .

16. E. LOHMEYer - W. Schmauch, Mattäus 409; así también: M.J. LAGRAnge, Matthieu 514; CH. H.DoDD, e.c., 106s; X LEON-DUFOUR, o.c., 127 (trad. españ., 140). 
quio con las mujeres y el abrazo de sus «pies» por aquellas; ya el hecho mismo de «salirse al encuentro de Jesús», como durante su ministerio mesiánico. Le «salió al encuentro un hombre» endemoniado y «Marta» de Betania ${ }^{17}$ : El resucitado «Jesús» es una persona visible y concreta o activo y pasivo sujeto de corporales acciones: Pero es mucho más. Pues si «Jesús» tranquilizó -¡no temáis!"- amedrentados por Su poder divino de «caminar sobre el mar» -igesto exclusivo de Dios! o dominar sobre el diabólico dragón y la muerte ${ }^{18}$, fue porque aquellas reconocieron de algún modo en el Resucitado al divino Triunfador de la muerte y de su diabólico autor. Nada de extraño, por otra parte: En el contexto de la tradición post-pascual, las primeras Comunidades cristianas confesaron al Resucitado como el Vencedor de «la muerte» o al «Señor de los muertos» ${ }^{19}$, así como el Dominador del diabólico «señor de la muerte» o «príncipe de este mundo» ${ }^{20}$. Análogo señorío de «Jesús» resucitado debieron reconocer y confesar sus primeros videntes. Es pues normal, que Aquél les enviase -«iid!» a sus «hermanos» o discípulos, como primeras mensajeras o «anunciadoras» de su real resurrección corporal - «me verán!»-y de su triunfo sobre la muerte.

Análogo mensaje pascual, qué duda cabe, debieron «anunciar» evangelizadoramente muchas mujeres misioneras de la Iglesia primitiva ${ }^{21}$. Nada de extraño pues si, en el contexto histórico de la hodierna Iglesia misionera, la mujer cristiana es llamada con insistencia por el supremo Magisterio eclesial a seguir el ejemplo de quienes - itras María la Madre de Jesús!- fueron las prístinas predicadoras del cristianismo, colaborando en la urgente tarea evangelizadora de la Iglesia y en su «nueva evangelización» del neopaganizado mundo actual 22: ¿Que la mujer cristiana no desoiga ese apelo materno de

17. Mc 5,2 par; Jn 11,20. 30; Cf. 12,18; 4,5; Lc 14,31.

18. Mc 6,48-50par; Cf. Jb 9,8; 38,16. Acerca de ese significado simbólico del «mar» y el exclusivo dominio de Dios sobre él, Cf.: J. DE Fraine-P. Grelot, Mar. VTB 507s; R. KRATZ, Thálassa. EWNT II 313-16.315s (bibliogr.).

19. Cf. 1 Tim 1,10; Hebr. 2,9.15; Apoc 1,18; Rm 14,9.

20. Cf. Hebr 2,9.14; Jn 12,31 (=1,11); 14,30; Apoc 12,10; 20,1-3; Cf. 1Jn 3,8.

21. Muchas, en efecto, son mencionadas por Pablo: «PRISCA» o la misionera «colaboradora» de Pablo (Rm 16,3; Cf. Act 18,1-3.26); «JUNIA» o la «ilustre entre los» predicadores «apóstoles» (Rm 16,7; Cf. 1Cor 12,28 [=Ef 4,11]; 9,5; 2Cor 8,23; 11,5.13; Ef 2,20; 3,5; Fil 2,25: Cf. D. Müller, Apóstol. DTNT I 140-146.142; J. A. BüHner, Apóstolos. EWNT I 342-51: 349s: bibliogr.); "TRIFENA y TRIFOSA» así como «la amada PÉRSIDE» o quienes sobre todo evanglizadoramente «se fatigaron mucho en el Señor» (Rm 16,21; Cf. 1Cor 15,10; Gal 4,11; Fil 2,16; Col 1,27-29; 1Tim 4,10; 5,17 etc. A este respecto, Cf. F. HAUCK, Kopiáo: ThWNT III 827-829), sin olvidar a "EVODIA» y a "SINTIQUE», las cuales misionariamente «lucharon por el Evangelio al lado» de Pablo (Fil 4,2-3; Cf. Col 4,15; 1Cor 11,5).

22. El Magisterio hodierno, en efecto, reconoce en la mujer «la gran importancia de su participación... creciente en los diversos campos del apostolado de la Iglesia» (CONC.VAT. II, Decr. AA, III 9), así como «la indispensable contribución de la mujer a la edificación de la Igle- 
la Iglesia! ¡Que aquélla devenga -hoy como ayer- una valiente anunciadora de Cristo resucitado y resucitador de toda clase de muertos!

\section{B. Una tradición histórica}

La tradición pre-mateana sobre la anastasifanía de «Jesús» a las mujeres, añadámoslo, no es producto de la fe pascual o creación literaria de la Comunidad primitiva. Varios indicios objetivos de su texto, por el contrario, reflejan datos seguros de su historicidad substancial.

a) Que el Resucitado se manifestase junto a su sepulcro a varias mujeres -entre las cuales a «María la Magdalena» ${ }^{23}$ - o a las mismas, que previamente constataron el Sepulcro vacío y del mensajero celeste recibieron el anuncio pascual, ${ }^{24}$, es normal: La historicidad de esta cristofanía está garantizada por la respectiva de aquella angelofanía. A ello se suma el múltiple testimonio sobre la Cristofanía a «María la Magdalena» ${ }^{25}$.

b) Una historicidad corroborada por el evidente contraste de esa tradición anastasiofánica con la respectiva de la prístina confesión cristiana y tradición paulina sobre la aparición del Resucitado «a Cefas» y «a los Doce» así

sia, como lo hizo durante el ministerio de Jesús» y en la Iglesia primitiva (JuAN PABLo II, Exh. apost. ChL, IV 49; Carta apost; MD, V 16), siendo «necesario» que la pasada colaboración acti$v a$ de la mujer en el «crecimiento y santidad de la Iglesia» misionera, «se amplíe e intensifique... ante la urgencia de una «nueva evangelización» en el mundo hodierno: JUAN PABLo II, Exh. apost. ChL, IV 49; Cf. II 25-31; III 32-39; ID., Exh. apost. CT IX 66-71; PABLo VI, Exh. apost. EN, VI 70-73. Sobre María o «la Sierva del Señor» como «primera evangelizadora cristiana», Cf. S. SAbugal, La Iglesia, Sierva de Dios, Zamora 1986, 67-69.70.

23. Cf. Mt 28,1.9.

24. Mc 16,1-8 par.

25. Mt 28,1.9-10; Jn 20,21-18; f. Mc 16,9. Que Jesús «se apareció primero a María la Magdalena» (f. Mc 16,9; Cf. Jn 20,11-18) no contradice en rigor, suponer que lo haya hecho "ante todo a su santísima Madre» (M.-J. LAGRANGe, Marc, 449; a este respecto, Cf. H. HolzMEISTER, Num Christus post resurrectionem benedictae Matri apparuisset?: VD 22 [1942] 97-72; A. M. ScHUMAIER, Controversia de Christophania Batae M. Virgini die Resurrectionis concessa. Mar 8 (1945) 147-51, A. Fernandez, Vida de nuestro Señor Jesucristo, Madrid 1954, 704s; P. BENoIT, o.c., 319; M. J. Gruenthaner, María en el NT: «Mariología» ed. J. B. Carol, Madrid 1964, 108: bibliogr.); aunque ningún texto del NT lo menciona ni, por tanto, debe subrayarlo el exegeta, éste si puede sumarse -como el autor de estas líneas lo hace- a «la piedad de los hijos de la Iglesia», quienes, «tienen por seguro que Cristo se apareció ante todo a su santa Madre» ((M.-J. LAgrange, L'Évangeli de Jésus-Christ, Paris 1939, 586), silenciando aquella Cristofanía los Evangelistas por parecerles obvia o por no necesitar una mención particular de aquella quien, -María- permaneció «de pie junto a la Cruz» (Jn 19,25), y por tanto no se había escandalizado del Crucificado. Estas y otras razones aducen autores antiguos (C. Sedulio, Paulino de Nola, Ruperto Abad, san Alberto M., san Ignacio de Loyola, san Pedro Canisio, J. Maldonado, Francisco de Toledo, F. Suárez, Cornelio L., Benedicto XIV: Cf. U. HolzmeIsTer, a.c., 98s) y modernos (Th. Zahh, M. Albertz, A. Loisy, L. Pirot, M.-J. Lagrange, J. Huby, A. Fernández, P. Benoit y otros): Cf. U. HolzMEISTER, a.c., 99. 
como a otros hombres y, entre ellos, a Pablo ${ }^{26}$. Un contraste, por lo demás, no contradictorio: El silencio de las mujeres por la prístina confesión cristológica obedece a la necesidad de apoyar la fe pascual sobre todo en el sólido testimonio de los Discípulos o Apóstoles, quienes eran sin duda los principales testigos de la identidad entre el Maestro o el Jesús histórico y el Cristo resucitado; la omisión de aquéllos por Pablo responde asimismo a su incapacidad jurídica para dar testimonio válido y creíble -así las consideraba entonces el Judaísmo- sobre la realidad corporal del Resucitado, testimonio que precisamente Pablo intenta subrayar ${ }^{27}$. Pero el mencionado contraste subsiste y a el se suma la clara desintonía de aquella tradición con muchas características de las primitivas tradiciones pascuales: Ausencia de argumentos bíblicos así como de títulos y confesiones cristológicas, falta de reflexión teológica sobre la eficacia salvífica de la Resurrección y sobre la modalidad corporal del Resucitado. Lo que significa: La Comunidad primitiva no pudo crear una tradición, francamente disonante con la expresión de su fe pascual. Los orígenes históricos de aquella tradición son pues otros. ¿Se remontan acaso al mismo Evento trasmitido?

c) Digamos de inmediato, que la tradición anastasiofánico designa al Resucitado simplemente «JESUS» o como le nombró la tradición histórica sobre la angelofanía pascual ${ }^{28}$, nombre personal muy frecuente en el contemporáneo Judaísmo palestinense ${ }^{29} \mathrm{y}$, por tanto, designación normal del mesiánico «Jesús» histórico: Con él se identifica en lo esencial al «Jesús» resucitado corporalmente o quien, tras «salir al encuentro» de sus videntes, femeninas, dialoga con quienes «abrazaron sus pies» ¡Un gesto de agradecida veneración femenina para con el Resucitado, del todo natural o en sintonía con lo que pudo ser la realidad histórica del evento! Pues prolonga el análogo gesto histórico de quienes, durante el ministerio mesiánico de Jesús, «cayeron» o «se postraron a sus pies» ${ }^{30}$ ¡ ¡El venerado Resucitado se identifica fundamentalmente con el reverenciado Jesús histórico!

d) Por lo demás, varios indicios objetivos de aquella tradición anastasiofánica reflejan una marcada coherencia o sintonía con la lengua materna de Jesús así como con las características de su lenguaje o habitual modo de

26. 1 Cor $15,5-8$.

27. Así con J. GNILKA, Matthäus II 496.

28. Mc 16,6 (=Mt 28,5).

29. Cf. S. SABugal, Credo 317 (bibliogr.).

30. Así Jairo (Mc 5,22=Lc 8,41), la mujer sirofenicia $($ Mc 7,35) y el curado leproso samaritano (Lc 17,16), «María la hermana de Lázaro (Jn 11, 32; Cf. 12,13) y la «mujer» pecadora (Cf. Luc 7,38$)$. Con unos y otras «cayeron a los pies» del Jesús histórico o de «una Persona concreta, el similar gesto de las mujeres para con el Resucitado refleja «una implícita seguridad de que hay una Persona real ante ellas». CH. H. DoDD, e.c., 106 (lo cursivado es nuestro). 
hablar. Así ya los numerosos semitismos armenizantes: Eso son la reiterada construcción paratáctica ${ }^{31}$ y el part. presente «diciendo» ${ }^{32}$; el presente histórico «les dice» ${ }^{33}$ y la expresión «no temáis» ${ }^{34}$; finalmente, el saludo griego «chaírete» (= ¡alegraos!) reproduce con toda probabilidad su correspondiente arameo «sumehán» (¡alegraos!) ${ }^{35}$... ¡Así pudo expresarse quien -Jesústuvo por lengua materna el arameo palestinense! ${ }^{36}$. Añadamos seguidamente, que los frecuentes imperativos - «alegráos» $\mathrm{y}$ «no temáis», «id» $\mathrm{y}$ «anunciad»-reflejan el característico lenguaje «imperioso» de Jesús ${ }^{37}$ con su lenguaje sintonizan asimismo, y en particular, la tranquilizante expresión «ino temáis!» ${ }^{38}$, el imperativo «id» ${ }^{39}$ y la designación de los discípulos como «hermanos» suyos ${ }^{40}$. No hay duda: La detectada tradición anastasiofánica, claramente semítica y sintonizante con la lengua propia de Jesús así como su característico modo de hablar, reproduce en lo esencial "la realidad del Evento» pascual trasmitido ${ }^{41} \mathrm{y}$, por tanto, ha de valorarse como sustancialmente histórico ${ }^{42}$.

32. «»Legôn». Cf. M.-J. LAGRAnge, MatthieuLXXXIX.

33. Un semitismo hebraico o aramaico: Cf. M.-J. LAGRANGE, Marc CXII; V. TAYLOR, Mark 64 (trad. españ., 69).

34. Reproduce su correspondiente hebrea (= «al tîraú») o arama (= «lo tidhalún»).

35. El verbo arameo «sámáh» (=alegrarse), en efecto, es usado frecuentemente -con idéntico significado- por el Judaismo qumránico y rabbínico (Cf. H. ConZELMANN, Chaíro: ThWNT IX 354s). El Targúm usa también, a este respecto, el imperativo aramaico «bî ú» (=alegráos: $T g J l$ 2,23), empleando asímismo la literatura de Qumrân el imperativo aramaico «hagelnáh» (1QM 12,13): Cf. H. ConZELMANN, a.c., 354.

36. Cf. S. Sabugal, Abbá. La Oración del Señor, Madrid 1985, 317-23: 321ss (bibliografía: 321, n. 21).

37.Cf. H. SCHÜRMAnN, Die Sprache des Christus: Bz 2(1958) 54-84: 80-82.

38. «Me phobeîsthe» es una expresión semitica (TgPIGén 15,1; 21,17 TgPIDt 1,20 Cf. G. WANKe, Phobéo: ThWNT, IX 119) y frecuente en labios de Jesús (Mc 6,50 par; Mt 10,26.28. 31 [Lc 12,28]; 17,7; Cf. Mc 5,36; Lc 5,10; 12,7.32), pero ignorado por los extraevangélicos escritos del NT (sólo análoga en: 1Pe 3,14; Apoc 1,17).

39. El imperativo «hypagéte» (=id) y «hypage» (=va) es usado «en el NT casi exclusivamente en labios de Jesús (=Mc 13, Mt 20, Lc 2, Jn 3); siendo propio de su «lenguaje imperioso»: H. SCHÜRMANN, a.c, 81.

40. La designación usada por los Evangelistas siempre en labios de Jesús (Mc 3,34 par; Mt $25,40 ; 28,10)$ sintoniza con su concepción sobre «el reinado de Dios» y su nuevo Pueblo elegido (Mc 3,34 par): Cf. M-J. LAgrange, Marc 78; E. LoHMEYer, Markus (1963), 81s; V. TAYlor, Mark $^{2} 247$ (trad. españ., 280); J. JEREMIAS, Theologie NT 166 (trad. españ., 201).

41. J. SCHNIEWIND, Matthäus 274 (lo cursivado es nuestro).

42. «Que Jesús se haya aparecido también a sus discípulas -y no sólo a sus discípulos- no ha de excluirse en absoluto» (J. GNILKA, Matthäus II 496). Los indicios objetivos del previo análisis histórico-redaccional y tradicional del texto mateano muestran ser exegéticamente superficial y científicamente inválido considerar aquel texto de «carácter legendario» (H. GRASs, Ostergeshehen 28) o atribuir sus orígenes a la redacción mateana». F. NEIRYNCK y J. KREMER, l.c., (supra, n. 15). 
Resumiendo los precedentes análisis histórico-redaccionales y tradicionales sobre la pascual Cristofanía del evangelista Mateo a las mujeres, podemos decir: La ciertamente marcada redacción literaria de esa cristofanía por Mateo, sin embargo, no es creación redaccional del Evangelista; éste elaboró literariamente, más bien, una breve tradición anastasiofánica, en la que -entre otros casos- no se mencionaba el mandato del Resucitado sobre la «ida» de sus discípulos «a Galilea»; la primitiva Comunidad cristiana -añadámoslo- no pudo crear esa tradición, cuyo texto acusa una franca desintonía o contraste con muchos característicos datos y expresiones de su fe pascual; y tanto la designación del Resucitado no con un título cristológico sino con el nombre del histórico y crucificado «Jesús mesiánico», como la coherencia o acorde de aquel texto con la lengua y estilo propios del Maestro, son otros tantos indicios objetivos de que la mencionada tradición se enraiza en el firme subsuelo del anastasiofánico Evento acaecido ó sustancialmente histórico. Lo que significa: En la historia se enraiza la primera aparición del Resucitado y, por tanto, su misma Resurrección o la piramidal cima de la historia salvífica y el fundamento de la fe cristiana, el dogma central del símbolo Apostólico y el eje del Cristianismo. ¡La espiritualidad esencialmente pascual del cristiano debe pues, fraguarse o robustecerse, mediante el frecuente «encuentro» personal con el Resucitado, y por cierto, en los eventos de la propia historia!.

\section{LA CRISTOFANIA A «LOS ONCE»DISCIPULOS (Mt 20,16-20)}

El relato anastasiológico de Mateo culmina y se concluye con esa aparición del Resucitado a los «Once discípulos» y su evangelizadora misión universal. Ya hemos visto la interpretación de ese Evento pascual por la redacción mateana ${ }^{1}$. ¿Late tras éstas una tradición pre-matena de historicidad sustancial?

\section{A. La pascual tradición evangélica}

Digamos de inmediato, que ese anastasiofánico relato mateano no puede ser creación literaria de Mateo: Varias de sus centrales concepciones teológicas - «el Reino de los cielos» y «la Iglesia» como nuevo «Pueblo» de

1. Cf. S. SABugAL, La resurrección de Jesús en el evangelio de Mateo (Mt 28, 1-20): Salesianum 53 (1991) 467-78: 473ss. 
Dios, el cumplimiento del At en el Jesús mesiánico y la polémica antijudaica- así como sus características títulos cristológicos -«el Mesías» y el «Descendiente de David», el «Rey de los judíos» y «el Hijo de Dios»- están del todo ausentes en ese relato pascual. Por lo demás:

a) Un detenido análisis literario de ese relato muestra que, junto a indiscutibles datos característicos del vocabulario y estilo mateano, existen otros muchos datos extraños a su redacción literaria. En efecto, Mt redactó el v. 16 añadiendo «discípulos» ${ }^{2}$, así como «a la Galilea» ${ }^{3}$ y «a el monte» ${ }^{4}$; los demás vocablos no son característicos suyos y, por tanto, ésta sería la tradición por él usada: «Los Once fueron al lugar, que les ordenó Jesús» ${ }^{5}$. El v. 17 fue marcadamente redactado por $\mathrm{Mt}$, con las adiciones «adoraron» $\mathrm{y}$ «pero algunos vacilaron» ${ }^{6}$; es pues tradición pre-mateana: «y lo vieron» ? Menos acusada es la redacción del v. 18 pero Mt, con la sola adición del participio «acercándose» $;$; todo lo demás es tradición evangélica: «Y Jesús les

2. Mt identifica «los discípulos» con «los Doce» (Mt 10,1; 11,1;20,17; Cf. G. STRECKER, o.c., 191-93; L. LANGE, o.c., 308-9.396s; W. SCHENK, o.c., 342s), respondiendo al previo relato sobre el trágico fin de «Judas» (Mt 27,3-10) la identificación de aquellos con «los Once» (Mt 28,16a), así designados por la tradición pre-mateana (Mc 16,20; Lc 24,9-33; Act 1,26; 2,14): Contra G. STRECKER , o.c., 208; J.P. MEIER, o.c., 408.

3. $\mathrm{Si}$ «Galilea» (=Mc 12, Mt 16, Lc 13) es característico símbolo teológico de Mt (Cf. E. LOHMEYER, Galilea and Jerusalem, Göttingen 1936, 16; G. STRECKER, o.c., 93-99; J. LANGE, o.c, 358-85: 385; W. SCHENK o.c., 107s), la frase «a la Galilea» (Mt 28,16) reasume literalmente la previa orden del «ángel» y del Resucitado (Mt 28,7.10): Así con G. STRECKER, o.c., 208; P. J. MEIER, a.c., 408.

4. Vocablo y tema característico de Mt («monte»: Mc 11, Mt 16, Lc 12; «el monte»: Mt 5,1; 8,1: 14,33 par; 15,29; 17,9par; 28,16): Cf. E. LOHMEYER, o.c., 16; E. LOHMEYER - W. SCHMAUCH, Matthaus 414; G. STRECKER, o.c, 375s.

5. A la designación tradicional «los once» (Cf. supra, n.2) se suman los verbos «ir» (=«poreúesthai»: Mc 3, Mt 29, Lc51+Act 37) y «ordenar» («tássein»: Mc 0, Mt 1, Lc 1+Act 4) pues en el previo contexto mateano nada prepara esa «orden» de Jesús: Así con P. MEIER, a.c., 409; contra: G. STRECKER, o.c., 98.208; J. LANGE, o.c., 448-50; R. H. GRUNDRY, Matthew 593s. «Ir al lugar» puede ser tradición premateana: Act 12,17; 27,8; Cf. Rm 15,23; Hebr 11,8, y otros autores.

6. Si el verbo «adorar» (=«proskynéo»: Mc 2, Mt 13, Lc 2+Act 4) es característico de Mt (Cf. E. LANGE, o.c., 370-71.472-75) y en 28,9.17 expresa la «reacción a la epifanía» del Resucitado (W. SCHENK, o.c., 422), el uso del verbo «distátso» (=«dudar» y «vacilar»: Cf. H. G. LIDDELR. SCOTT, Lexicon 437; W. BAWER, Wörterbuch 396) es exclusivo neotestamentario de Mt $(14,31 ; 28,17)$ y, por tanto, del «probable origen mateano»: G. STRECKER, o.c., 475-78; J.P. MEIER, a.c., 409.

7. Si la construcción «viéndolo» es mateana (Mt 8,34; 14,26, [=Mc 6,49]; 28,17), en Mt 28,17 no expresa la insistencia previa (Mt 28,7.10) de la «visión» y, por lo demás, «ver» al Resucitado es tradición pre-mateana (1Cor 9,1; Act 22,14.15=26,16; Cf. 13,31; 1Cor 15,5-8; Lc 24,34 etc.): Así con J. P. MEIER, a.c., 409; contra R. H. GRUNDRY, Matthew 594.

8. Si el verbo «prosérchesthai» (=Mc 5, Mt 52, Lc 10+Act 10) es característico de Mt (Cf. J.C. HAWkins, o.c., 7; M. J. LAGRANGE, o.c., CVII; W. SCHENK, o.c., 422), el imper. «prosélthon» (=acercándose), referido a Jesús, es en elNT exclusivo de Mt $(17,7 ; 28,18 \mathrm{a})$; este último 
habló, diciendo ${ }^{9}$ : Me fue dada ${ }^{10}$ toda potestad ${ }^{11}$ en cielo y sobre tierra ${ }^{12}$. Todo el v. 19 a es tradición pre-mateana: «yendo pues ${ }^{13}$, haced discípu los ${ }^{14}$ a todas las naciones ${ }^{15}$. También el v. $19 \mathrm{~b}$ se remonta a la tradición pre-

uso de aquél es, pues, «claramente redaccional»: G. STrecker, o.c., 209; Cf J. P. MeIer, a.c., 409s; J. LANGE, o.c., 479; R. H. GRUNDRY, Matthew 594. Sobre la previa redacción de «prosélthon» (v.9): Cf. supra 000, n. 4.

9. Si el verbo «laléin» (=Mc 21, Mt 26, Lc 31+Act 60, Jn 60, Ep. paul. 60) no es característico de Mt y sí es muy usado por la tradición pre-mateana (=p. paul.+Kérygmas de Act), no es exclusivo de Mt el uso de «laleín»+«légein» (Cf. Mc 6,50; Lc. 24,3) y la construcción semítica «elálesen... légon» (Mt 13,3; 14,27; 23,31; 28,18; Jn 8,12; Act 8,26; 26,31; 28,25; Apoc 4,1; 10,8; $17,1 ; 21,9)$; ésta se remonta a la tradición pre-mateana: contra G. STRECKER, o.c., 209; J. P. MEIER, a.c., 410; J. LANGE, o.c., 480; R. H. GRUNDRY, Matthew 595.

10. Si el uso del verbo «didónai» no es mateano (=Mc 39, Mt 56, Lc 60+Act 35, Jn 76, Ep. paul. 72), el del pasivo «edóthe» (=me fue dada) se remonta a la tradición pre-mateana (Cf. Jn 1,$17 ; 12,5 ;$ Gal 3,21; Ef 4,7; Apoc 6,4; 8,3.11; 9,1.3.5.11,1.2; 13,5.7.14.15; 16,8; 19,8; 20,4); y aunque aquel «pasivo divino» es exclusivo de Mt 28,18 en labios de Jesú, pudo ser usado por el Resucitado (¡en refeencia a Dan 7,14!), como lo fue característico del Jesús histórico: Cf infra, n. 81.

11. No son característicos de Mt el adj. «pâs» (=Mc 67, Mt 128, Lc 152, Jn 460) ni el sust. «exousía» (=Mc 10, Mt 10, Lc 16+Act 7, Jn 8, Ep. paul. 27); y si la «exousía» (potestad) de Jesús es reiteradamente mencionada ya por la tradición pre-mateana (Mc 1,22. 27par; 2,10par; 11,2829.33par; Ef 1,21s; Col 2,10; Fil 2,9-10; Rm 14,9; Act 10,36.42; 1Pe 3,22; Cf Jn 5,27; 10,28; 17,2; apoc 12,$10 ; 18,1)$, también es tradicioal $(=\mathrm{Q})$ el paralelo aserto de Jesús: «iTodo (=pánta) me fue entregado (=paredóthe) por mi Padre!». (Mt 11,27a=Lc 10,22a). La «postestad total» del Resucitado (Mt 28,18b; Cf. Dan 7,14b-c) es pues un dato de la tradición evangélica. Así con: G. STRECKER, o.c., 209; J. P. MEIER, a.c., 413; R. H. GRUNDRY, Matthew 595; contra: E. LoHMEYER - W. SCHMAUCH, Matthäus 423; J. LANGE, o.c., 25-169: 93.166.

12. La conjunción u oposición del «cielo» y «tierra» no es característica de Mt, y sí se remonta a la tradición o fuente pre-mateana: Mc (Mt 24,35= Mc 13,31); Q (Mt 5,18 = Lc 16,17; Mt 11,25 = Lc 10,21), tradición judeo-cristiana (Mt 5,34-35 = Sant 5,12; Mt 6,10: Cf. S. SABugAL, Abbá 254s, bibliogr. n. 25: muchos autores; a esa tradición se remontan también los textos en plural: Mt 16,19: Cf. G. Dalman, Die Worte Jesu, Leipzig 1930 174-78; J. GnIlKA, Matthäus II 69; Mt 18,18: Cf. G. Dalman, I.c.; J. GNILKA, Matthäus II 141). Es pues exacto afirmar, que «en cielo y sobre tierra» (Mt 28,18b) suscita una impresión no mateana» o se remonta a la «tradición» de Mt: G. STRECKER, o.c., 209; J. P. MEIER, a.c., 414. Contra J. LANGE, o.c., 96-149: 146; R. H. GRUNDRY, Matthew, 595. Los precedentes análisis muestran ser del todo erróneo afirmar que Mt «mismo creó el v. 28,18»: J. LANGE, o.c., 147.

13. Si el verbo «poreúmai» (=ir) no es mateano (=Mc 3, Mt 29, Lc 51+Act 37), tampoco lo es el uso del imperativo «poreuthontes» (=Mc 1, Mt 6, Lc 6) en labios de Jesús $(M t 3=9,13 ; 11,4$ [=Lc 7,22]; 28,19; Lc 4 = 7,22 [=Mt 11,4]: 13,22; 17,4; 22,8) a sus discípulos (Mc 16,15; Mt 28,19a; Lc 22,8): Puede remontarse a la tradición $(=\mathrm{Q}+\mathrm{f} . \mathrm{Mc})$ pre-mateana (contra J. LANGE, o.c., 305s), a cuyo origen tradicional se debe asimismo la conjunción «oûn» (=Mc 5, Mt 57, Lc 31+Act 62, Jn 194, ep. paul. 112). Fuera de Mt 28,19a el Er ingelista ignora la construcción «poreuthéntes oûn», proveniente sin duda de la tradición pre-mateana: J. LANGE, o.c., 36s; contra R. H. GRUNDRY, Matthew 595.

14. El uso del verbo ««mathetéuo» (=Mc 0, Mt 3, Lc 0+Act 1, Jn 0, Ep. paul. 0) es característico de Mt (13,52; 27,57; 28,19: Cf. W. SCHENK, o.c., 342, bibliogr.); relacionado con la evangelización o kérygma, sin embargo (sólo en Mt 28,19; Act 14,21), puede ser pre-mateana tradición kerygmática: Contra G. STRECKER, o.c., 209, n. 4: J. LANGE, o.c, 308-10. 325s; R. H. GRUNDRY, Matthew 595.

15. Si el uso del vocablo «éthnos» (=Mc 6, Mt 15, Lc 13+Act 43, Jn5, Ep. paul. 54) se remonta a la tradición kerygmática (Act) y paulina, la construcción "pánta ta éthne» (Mt 6,32 [=Lc 12,3]; 24,14 [=Mc 13,10]; 25,32; 28,19=Cf. Mc 16,15: «páse te stísei») no es redaccional y sí 
mateana ${ }^{16}$ : «Bautizándolas ${ }^{17}$ en el nombre ${ }^{18}$ del Padre y del Hijo y del Espíritu Santo» ${ }^{19}$. En el v. 20a reprodujo fielmente Mt su tradición evangélica ${ }^{20}$ :

misión universal a la tradición apostólica Gal. 2,8; rom 10-11; Ef. 2,11-18; Act 10+11.15 etc). Así con: E. Klostermann, Matthäus 232; E. Lohmeyer - W. Schmauch, Matthäus 424; J. SchnieWIND, Matthäus 277. Es pues del todo inexacto atribuir todo el v. 19a a la redacción de Mt: Contra G. STRECKER, o.c, 209; J. P. MEIER, a.c., 410; R. H. GrUNDRY, Matthew 595.

16. Así con varios comentarios a Mt (W. C. AlLEN 300; P. BonNARd 416s: trad. españ., 620s; J. SCHNIEWIND 277s; W. GRUNDMANN 579; E. LOHMEYER - W. SCHMAUCH, 423; J. GNILKA, II 509) y estudio del texto mateano (G. STRECKER, o.c., 209; J. LANGE, o.c, 313; J. P. MEIER, a.c., 410.414; C. R. BEASLEY - Murray, Baptism in the New Testament, London 1963, 77 92:83s; G. BARTH, El Bautismo en el tiempo del Cristianismo primitivo, Salamanca 1981, 1318:17s.). En efecto, la paralela fórmula bautismal de Did 7,1 es independiente de Mt 28,19b (E. LOHMEYer -W. SCHMAUXH, Matthäus 423; Cf. J. SCHNIEwInd, Matthäus 278; W. Grundmann, Matthäus 579) y reproduce una "tradición» o «un uso establecido» (J. AUDET, La Didaché, Paris 1958, 209, 364; Cf. W. Rodorf - A. Tullier La Doctrine des Douze Apôtres [SC 248], Paris 1978,35). Del todo inexacto es valorar el v.19b como «una interpolación antigua»: E. KLOSTERMANN, Matthäus 232.

17. El uso neotestamentario del verbo «baptísein» (=Mc 12, Mt 7, Lc 10+Act 21, Jn 13, Ep. paul. 13) es tradicional y no propio de $\mathrm{Mt}$, quien ignora las expresiones tradicionales «baptísein autoús» (Act 10, 48; Cf. 10,47;1Cor 1,14) y «baptísein eis to ónoma» (Act 19,5; Cf. 1Cor 1,13.15): Contra J. LANGE, o.c., 310-13: 310; R. H. GRUNDRY, Matthew 596.

18. A la tradición cristiana se remonta el uso de «ónoma» (=Mc 15, Mt 22,Lc 34+Act 60, Jn 25, Ep. paul 21) y «to ónoma» (=Mc 8, Mt 13, Lc 18, Jn 20, Ep. paul. 16), así como la expresión «eis to ónoma» (sólo en Act 19,5; Cf. 1Cor 1,13.14), la cual no es «a favorite phrase of» Mt: Contra R. H. GRUNDRY, Matthew 596.

19. No son característicos de Mt y si pertenecen a la tradición pre-mateana el uso de «el padre» (=Mc 18, Mt 64, Lc 56+Act 35, Jn 137, Ep. paul. 63) y «el Padre» (=Mc 5, Mt 40, Lc 14+Act 3, Jn 115, ep. paul. 42), «el hijo» (=Mc 34, Mt 89, Lc 77+Act 21, Jn 55, Ep. paul. 40) y «el Hijo» (=Mc 8, Mt 17, Lc 10+Act 3, Jn 28, ep. paul.17), «espíritu» (=Mc 23, Mt 19, Lc 36+act 70, Jn 24, Ep. paul. 146), «el Espíritu» o «el Espíritu de Dios» etc (=Mc 2, Mt 7, Lc 4+Act 11, Jn 11, Ep. paul. 55) y «el Espíritu Santo» (=Mc 4, Mt 5, Lc 13+Act 41, Jn 3, Ep. paul.14). Es pues del todo inexacto calificar de «mattheanisms» los nombres de las tres divinas Personas (R. H. GRUNDRY, Matthew 596), claramente mencionados juntos ya por las Ep. paulínas y otros premateanos escritos neostestamentarios (2Cor 13.13; Ef 4,4-6; 1Pe 1,2; Cf. Act 2,38-39; 10,42-44; Gal 4,6; 1 Cor 6,11; 12,4-6; 2Cor 1,21-22; Rom 5,5-6.8; 8,14-17; Hebr 2,3-4; 6,4-6; 1Pe 4,4; Jds 20 21 etc): Cf. H. RAHNER, Dreifaltigkeit: LThK III 547; K. RAHNER, Trinidad: SM V 733s; F. J. SCHIERSE, La revelación de la Trinidad en el NT: MS II.1 (Madrid 1969(159-62; M. SCHMAUS, Trinidad: CFT II 827s; A. W. WAINWRIGHT, La Trinidad en el NT, Salamanca 1976, 283-90; S. Sabugal, Credo. La fe de la Iglesia, Zamora 1986, 339s: Trad.ital., Roma 1989, 262 (bibliogr.). Es pues exacto afirmar, que «la fe en la Trinidad es tan antigua como» el Cristianismo: W. C. AlLEN, Matthew 306; CF. J. SCHNIEwIND, Matthäus, 278.

20. Contra G. STRecker, o.c., 209; J. LANGe, o.c., 316-24:316-18; J. P. Meier, a.c., 410; R. H. GRUNDRY, Matthew 597.

21. Si «disdákontes autoús» (Mt 28,20a) es único en el NT, a la tradición pre-mateana se remonta el uso de «didáskein» (=Mc 17, Mt 14, Lc 17+Act 16, Jn 9, Ep. paul.15) y «didáskontes» (=Mc 1, Mt 2, Lc 0+Act 3, Jn 9, Ep.paul.3) así como la expresión «didáskein autoús» en labios de Jesús (=Mc 6, Mt 4, Lc 1, Jn 1); esta última no es mateana (Contra E. LOHMEYER - W. ScHMAUCH, Matthäus 423; J. LANGE, o.c, 316s; R. H. GRUNDRY, Matthew 597). A la tradición cristiana pertenece asimismo el uso del verbo «teréin» (=Mc 0, Mt 6, Lc 0+Act 8, Jn 18, Ep.paul.7), el 
«Enseñándoles a observar ${ }^{21}$ todo cuanto ${ }^{22}$ os mandé» ${ }^{23}$. Finalmente $\mathrm{Mt}$ redactó el v. $20 \mathrm{~b}$ añadiendo solamente «la consumación del mundo» ${ }^{24}$. Es pues tradición pre-mateana: «y he aquí ${ }^{25}$ que yo estoy con vosotros ${ }^{26}$ todos los días ${ }^{27}$, hasta el fin» ${ }^{28}$. Esta sería pues la tradición usada por $\mathrm{Mt}$, al redactar la anastasiofanía de Jesús a los «Once discípulos»:

cual no es por tanto «un mateanismo»: Contra R. H. GRUNDRY, Matthew 597; así también G. STRECKER, o.c., 209; J. P. MEIER, a.c., 410.

22. Si la construcción «pánta hósa» (=Mc 3, Mt 6, Lc 2+Act 1, Jn 4, Ep.paul.0) es ligeramente mateana (Cf. W. SchENK, o.c., 377), no lo es el uso de «pâs» (=Mc 67, Mt 128, Lc 152+Act 170, Jn 63, Ep. paul.460) ni de «hósos» (=Mc 14, Mt 15, Lc 10+Act 17, Jn 9, Ep. paul.27); por lo demás, los cuatro Evangelistas atestiguan el uso de «pánta hósa» en labios de Jesús (Mc 11,24 [=Mt 21,22]; 12,44; Mt 7,12; 13,44.46; 18,25; 23,3; Lc 18,12.22; Jn 16,15; 17,7): ¡Pudo haberla usado el Resucitado! (Mt 28,20a).Contra G. STRECKer, o.c., 409; J. P. MeIER, a.c., 410; R. H. GRUNDRY, Matthew 597.

23. A la ligera preferencia matena del verbo «entéllomai» (=Mc 2, Mt 4, Lc 1+Act 2, Jn 3, Ep.paul. 2) se suma el casi unánime testimonio evangélico de su segundo empleo por Jesús (Mc 10, 3 [=Mt 19,7]; 13,34; Mt 17,9; Jn 14,31; 15,14.17), pudiendo por tanto haberlo usado el Resucitado (Mt 28,20a). Contra: G. STRECKer, o.c., 209; J. P. MEIER, a.c., 410; R. H. GRUNDRY, Matthew, 597.

24. La única frase redaccional exclusiva neotestamentaria de $\mathrm{Mt}(=5 \mathrm{x})$ y $\mathrm{Hebr}(=1 \mathrm{x})$ : $\mathrm{Cf}$. W. SCHENK, o.c, 17. Del todo inexacto es pues atribuir todo el v. $20 \mathrm{~b}$ a la redacción mateana: Contra E. LANGE, o.c., 328-29.348s; J. GNILKA, Matthäus II 505.

25. La septuagentista exclamación neotestamentaria «kai idoú» (Cf. W. BAUER, Wörterbuch 733; P. FIELDLER, Die formel «und siehe» im NT, Mainz 1969 [bibliogrs.: 14-17]; H. GoLDSTEINI, Idoú: EWNT II 424s), aunque ligeramente característica de Mt (=Mc0, Mt 27, Lc 24+Act 11), no lo es aquí, pues en labios de Jesús atestiguan aquella exclamación Mt $(7,4 ; 20,28)$, Lc $(11,41 ; 13,30)$ y Q (Mt 12,41.42 = Lc 11,31.32) o la fuente de Mt y Lc (así con J. P. MEIER, a.c., 414))): ¡Pudo haberla usado la tradición pascual (Mt 28,20b; Cf. Lc 24,49a) sobre el Resucitado (así contra: G. STRECKER, o.c., 209; R. H. GRUNDRY, Matthew, 597). A quien con seguridad se remonta la exclamación «idoú», atestiguada en labios de Jesús por los cuatro Evangelistas así como por las dos fuentes (Mt+Q) mateanas (Cf. Mc 4,3 [=Mt 13,3]; 10,33par; 14,41.42 [=Mt 26,45.46]; Mt 10,16 [=Lc 10,3]; 11,8.10.19 [=Lc 7,25.27.34]; 12,18.49; 21,5 [=Zac 9,9 LXX]; 22, 4; $23,34.38$ [=Lc 13,35:]; 24,23 [=Lc 17,23]. 25.26; 25,6; Lc 6,23; 10,19; 13,3.16.32; 15,29; 17,21; $19,8.20 ; 22,10.21 .31 ; \mathrm{Jn} 4,35 ; 16,32)$, sin duda para «llamar la atención» á sus palabras o mensaje: H. SCHÜRMANN, a.c., 63.

26. Expresión única en el NT y, por tanto no necesariamente creada por Mt. Que el Resucitado está con un determinado apóstol («YYo estoy contigo!»: Act 18,0; Cf. 26,17) y con sus discípulos o creyentes es una concepción segura de la tradición cristiana (Gal 2,20;2Cor 12, 9; Rom 8,9-10; Ef 3,17; 2 Tim 3,11; 4,17; Mt 18,20; Cf. Mc 16,20; Jn 14,16.17.18.20.23; 15,1-5; 16,13-15), claramente reflejada ya en el perfecto del verbo «egeírein» (1Cor 15,4; 2Tim 2,8; Mc 16,14 = «fue y está resucitado»), así como en el frecuente aoristo ingresivo de los verbos «anístemi» y «egeírein» (Cf. S. SABUGAL, El vocabulario anastásico del NT: RevAg 30 (1989) 385-401:388 (n.14). 394 (n. 64). A esa tradición pascual puede remontarse el aserto de Mt 28,20b. Así con G. STRECKer, o.c., 209; contra: E. LOHMEYER - W. SChMAuch, Matthäus,423; J. P. MEIER, a.c, 410; R. H. GRUNDRY, Matthew 597.

27. Construcción sólo usada en el NT por Mt $(28,20 \mathrm{~b})$ y Lc $(1,75)$ : El hecho de no ser característicos de Mt los vocablos «pâs» (Cf. supra, n.22) y "heméra» (=Mc 27, Mt 45, Lc $83+$ Act 94 , Jn 31, Ep. paul. 50) muestra que aquella construcción no es redaccional y sí puede 
«Los Once fueron al lugar, que les ordenó Jesús (v.16) y lo vieron (v.17). Y Jesús les habló diciendo: ¡Me fue dada toda potestad en cielo y sobre tierra! (v.18). Yendo, pues, haced discípulos a todas las naciones, bautizándolas en el nombre del Padre y del Hijo y del Espíritu Santo (v.19); enseñándoles a observar todo cuanto os mandé. ¡Y he aquí que yo estoy con vosotros todos los días, hasta el fin!» (v.20).

Los precedentes análisis han mostrado que el relato mateano sobre la anastasiofanía de Jesús a «los Once discípulos» no es una casi total creación literaria del Evangelista ${ }^{29}$; el cual usó, más bien, una «tradición» previa ${ }^{30}$ y sólo por él ligeramente retocada ${ }^{31}$.

b) ¿Qué mensaje anastasiológico envuelve esa tradición anastasiofánica o cómo la interpretaron las primeras Comunidades cristianas? Estas debieron valorar la pronta obediencia de «los Once» o quienes, aceptando el previo anuncio de «las mujeres» (v.10), sin demora «fueron a donde les había preceptuado Jesús» (v.16), como paradigma de «la obediencia de la fe» propia de los «elegidos para obedecer a Jesucristo» o de quienes prontamente «obedecieron a la Buena Noticia» sobre el Resucitado ${ }^{32}$. A quien aquéllos sensiblemente «vieron» corporalmente resucitado (v.17), como lo «vio» Pablo

remontarse a la tradición pre-mateana. Así con J. P. MEIER, a.c., 414; contra R. H. GrUNDRY, Matthew 597.

28. Si el uso de la conj. «héos» (=Mc 15, Mt 48, Lc 28+Act 22, Jn 10, Ep.paul.13) es mateano (Cf. W. SCHENK, o.c.; 272s), su empleo en labios de Jesús por Mt (=28x) proviene a veces de sus fuentes evangélicas (=Mc 9, Q3), atestiguando también aquel uso el cuarto Evangelista $(=\mathrm{Jn} 4 \mathrm{x})$ : ¡Pudo haberla usado la tradición sobre el Resucitado! (Mt 28,20b; Cf. Jn 21,22). A la que puede remontarse «el fin» parusíaco (=«to télos»): Concepción segura de la tradición cristiana, usada por Jesús (Mc 13,7 [=Mt 24,6]; Mt 24, 14) y dos autores pre-mateanos del NT (1Cor 15,24; 1Pe 4,7).

29. Así contra: J. LANGE, o.c., 25-486 (una breve crítica objetiva le ofrece J. P. MEIER, a.c., 411-16); J. D. KIngsBuRY, The composition and Christology of Mt 28,16-20: JBL 93(1974) 57384:579; R. H. GRUNDRY, Matthew 593-97. A los objetivos indicios literarios supraofrecidos contra la creación de Mt 28,16-20 por el Evangelista, se suma la disparidad total entre el relato mateano sobre la misión «israelítica» de «los Doce» (Mt 10,1-42) y éste sobre la misión a «todas las naciones» de «los Once»; en el que, por lo demás, se ignora la figura de «Pedro» o el «primero» de los Apóstoles (Mt 10,2), cuya predominente mención mateana (=Mc 11, Mt 23; Lc 18) corresponde al puesto preeminente de Pedro en Mt: Cf. J. A. FitzMYer - M. M. Bourke, Pedro en el evangelio de $M t$ : «Pedro en el NT» (ed. R. E. Brown-K. P. Donfried-J. Reuman), Santander 1976, 77-104: 77.102; R. PESCH, Pétros: EWNT III 193-20:196s.

30. Así con: CH. H. Dodd, The appearences, 106; J. GnilKA, Matthäus, II 505. Más moderados: G. STRECKER, o.c., 208-10; J. P. MEIER, a.c., 408-16. Escéptico J. KREMER, Osterevangelien 91.

31. En sontonía con los autores citados (supra, n.29), menciona también «el fuerte cuño» mateano J. GNILKA, l.c.

32. $\operatorname{Rm} 1,5(=16,26) ; 1$ Pe 1,2; Rom 10,16.

33. Cf. supra, n. 7 (textos). Ese significado tiene también el verbo «oráo» en su tradicional contexto anastasiológico: Cf. Mc 16.5-7 par; Lc 24,27; Jn 20,18.20. 
y Cefas así como otros cualificados testigos oculares ${ }^{33}$. Una visión del «Jesús» dotado por Dios «con toda potestad en cielo y sobre tierra» (v.18) o por Él constituído Plenipotenciario suyo, pues Dios lo exaltó sobre «toda dominación y potestad» y «todo lo pudo bajo sus pies» o dominio, constituyéndolo supremo «Señor» universal o «Señor de todos» y de todo ${ }^{34}$, de modo que «QUIEN, EN SITUACIONES EXISTENCIALES DE ESCLAVITUD RADICAL Y DE SOFOCANTE ANGUSTIA, DE INSOPORTABLE SUFRIMIENTO Y DE MIEDO A LA Muerte, 'InVOQUe El NOMbre del Señor' Resucitado y PlenipotenciaRIO 'SERA SALVO'!» ${ }^{35}$. Esta Buena Noticia predicaron sin duda «los Once»y, tras ellos, todos los enviados - «iid!» por Jesús resucitado. El paradigmático «apóstol» o enviado Pablo tenía conciencia plena de ello, asegurando que «Cristo... me envió... a predicar el Evangelio ${ }^{36}$. La misión evangelizadora de la Iglesia primitiva se enraiza por tanto en ese inicial «envió» del Resucitado. Una misión, por lo demás, absolutamente primordial en el quehacer de las primeras Comunidades cristianas: Tras el evento de Pentecostés, lo primero que hacen los Apóstoles es predicar a los «israelitas» la Buena Noticia de la resurrección de Jesús o su victoria sobre la muerte ${ }^{37} \mathrm{y}$, por mandato del «Espíritu» o del «Señor» resucitado, ir -«¡vete!»- a predicar ${ }^{38}$ aquel anuncio pascual a los paganos ${ }^{39}$.

Una misión que tiene por objeto «hacer discípulos» a los hombres (v. 19a): Obedeciendo sin duda, a ese mandato evangelizador de Jesús, en Derbe «Pablo y Bernabé hicieron bastantes discípulos» (=«matheteúsantes») o «cristianos» ${ }^{40}$, así designados efectivamente - «discípulos»- de modo gene$\mathrm{ral}^{41}$, e individualmente ${ }^{42}$ los creyentes en el Resucitado. Provenientes éstos de entre los judíos y, sobre todo de «todas las naciones paganas» (v.19a): Una evangelizadora misión universal inaugurada por Pedro ${ }^{43}$, para ser pro-

34. Ef 1,21-22 (=Col 2,10; 1Cor 15,25-27a); Fil 2,9-10; Rm 14,9; Act 10,36.42.

35. Rm 10,13; Act 2,21; Cf. 4,12.

36. 1 Cor 1,17 ; Cf. Act 22,$21 ; 26,17$.

37. Act 2,22-36; 3,13-26; 4,8-12; 5,22-32; 13,16-41.

38. Act 10,20 (=11,12);22,18.21; Cf. 26,17; 13,2-3.

39. Act $10,34-41 ; 17,18.22 .31$.

40. Act 14,21; Cf. 11,26 .

41. Cf. Act 9,1.19.26.38; 11,26.29; 13,52; 14,20.22.28; 15,10; 18,23.27; 19,9-30; 20,1.30; 21,4.16. Esa designación lucana de los cristianos (=«discípulos») es tradicional y se remonta sin duda a esa designación de los creyentes en el Resucitado por las primitivas Comunidades de Palestina: Cf. H. J. CADBury, Names for christians and christianity Acts: «The Beginnings of Christianity» (ed. F. J. F. JACKSON-K. LAKE), V. London 1933, 375-92: 376-78; K. H. RENGSTORF, Mathetés, ThWNT IV 462s.

42. Act 9,10 (Ananias). 36 (Tabitá); 16,1 (Timoteo); 21,16b (Mnasón).

43. Act 10,34-38; Cf. 15,7-11. 
longada sobre todo por Pablo ${ }^{44}$ y sus compañeros -hombres y mujeres- de apostolado ${ }^{45}$. Ese Kerygma, por lo demás, desembocaba y culminaba en «el bautismo» purificador de los pecados ${ }^{46}$, conferido como incorporación al (=«eis») «nombre» o vida «del Señor Jesús» ${ }^{4} 7$ y -según otra tradición judeocristiana- «al (=eis) nombre» o vida «del Padre y del Hijo y del Espíritu Santo» ${ }^{48}$. Una incorporación bautismal a la vida divina, completada con la «enseñanza» o catequética instrucción ${ }^{49}$ sobre «lo referente a Jesús» o «la fe en» Él ${ }^{50}$ así como sobre los preceptos del «Señor» ${ }^{51}$ resucitado. Cuya Compañía fiel o activa presencia tanto en la Comunidad de los creyentes como en

44. Gál 1,15-19 (Cf. S. SABugal, La Conversión de San Pablo, Barcelona 1976, 12-18); 2,89 [=Act 22,15; 26,17-18]; Rm 1,5.16; 3,28-30; 4,10-12; 9,23-31; 10,12-11, 32; Ef 2,11-18; 3,4-7; Col $1,5-6.21-23$; Act 17,18-34; 19,9-10.22-23; 20,1-3.6-10; 28,28-31.

45. Cf. Col 1,7; Act 13,46-49; 14,27; 16,29-32; 18,2-3.26; Cf. Rm 16,3-4.7.11b-12.

46. At $2,38.41 ; 8,12-13.16 .36 .38 ; 9,18(=22,16) ; 10,47-48 ; 16,15.33 ; 18,8 ; 19,5$; Cf. Gál 3,17; 1 Cor 1,13; 15,29; Rm 6,3; Ef 4,5; 5,26; Col 2,12; Tit 3,5; Hebr 6,2; 10,22; 1Pe 3,21. A este respecto, Cf.: A. Oepke, Bápto: ThWNT I 536-41; AA. VV. Le Baptême dans le NT: LumVie 56-57 (1956); C. R. BeAsley-Murray, Baptism in the NT, London 1963, 93-262; ID., Bautismo: DTNT I 160-66: 162-64; B. NEUNHEUSER, Bautismo: SM I 499-519: 501-4 (bibliogr.); J. BETZ, Bautismo: CFT I 154-71:155-58 (bibliogr.); G. BARTH, o.c., 40-141; W. BIEDER, Baptízo: EWNT I 459-69:463-68 (bibliogr.). «En las Comunidades cristianas el bautismo fue usado, sin duda, desde el principio», acompañado desde los origenes «al mensaje o anuncio del Evangelio»: A. OEPKE, a.c., 537; . R. BEASLEY-MURRAY, a.c., 162; Cf. ID., o.c., 93-99.

47. Act 19,5; Cf. 8,16; Rm 6,3; Gal 3,27; 1Cor 1,13 (Otras bautismales fórmulas cristológicas: Act 2,$38 ; 10,48)$. La mención del «Espíritu Santo» y de "Dios» en el contexto próximo de las bautismales fórmulas cirstológicas (Act 2,38; 10,44; 1Cor 6,11; 12,13; 2Cor 5,21-22; Gal 3,27; Cf. 4,6=Rm 8,14-15) es frecuente: Así con J. SCHNIEWIND, Matthäus 277s.

48. Cf. supra, nn. 17-19. Quizá "la bautismal fórmula cristológica» fue interpretada luego por la «bautismal fórmula trinitaria» (W. BIEDER, a.c., 464), dada la estrecha relación de «Dios» (Padre) y del «Espíritu Santo» con el bautismo conferido «en el nombre de Jesús» (Cf. supra, n.47), y la prístina fe trinitaria de la Iglesia: Cf. supra, n. 18.

49. $\mathrm{Rm} 6,11 ; \mathrm{Col} 2,7 ; 2 \mathrm{Jn} 9$, etc.: Cf. infra, n.50.

50. Tras la «predicación» o Kérygma, eso «enseñaba» en Éfeso Apolo y Pablo (Act 18,25; 20,21). Quien, «constituido» no sólo «heraldo y apóstol» sino también “maestro de los gentiles» (2Tim 2,7), tras su predicación visitaba «las iglesias para consolidarlas en la fe» (Act 15,16.41), mediante la «enseñanza» o instrucción (Cf. Col 2,7; Rm 14, 19) complementaria, impartida luego con sus Epístolas (Cf. 1Tes 4,1-2.9; 5,1-2-18; 2Tes 2, Iss; Gal 1,6-9; 3, Iss; 1Cor 1, 11ss; 5 Iss; 6, Iss; 7,Iss; 8,Iss; 11,2ss; 12,1ss; 15,1ss; Rm 3,8.31; Ef 2,11-3,7; Fil 1,12-18; Col 2,6-23 etc). Por lo demás, en las primitivas Comunidades cristianas existía el carisma de los «maestros»o instructores (1Cor 12,28; Ef 4,11; Cf. Act 13,1; Gal 6,6), encargados de «enseñar» o consolidar a los fieles en la fe (Cf. 1Cor 14,19; Gal 6,6; 2Tim 2,2), ministerio ejercido también por los «los obispos» y «presbiteros», exhortados por ello a «enseñar» a los creyentes (1Tim 3,2; 4,11.13.15,17; 6,2; 2Tim 2,24)«la enseñanza» (1Tim 4,13.16; 5,17; 6,1; 2Tim 3,10; 4,2; Tit 1,9) o "La enseñanza sana» y buena (1Tim 1,$10 ; 4,6$; Tit 1,$9 ; 2,1 ;$ Cf. 2 Jn 10 ) o esa «doctrina pura» sintonizante con «la piedad" (tit 2,7; 1Tim 6,3), que es «la doctrina de Dios» o «la doctrina de Cristo» (Tit 2,10; 2 Jn 9).

51. Cf. 1Cor 9,13-14 (Cf Mt 10,10par); 11,10-11.23-25; Gal 5,14= Rm 13,9 (Cf. Mc 12,36-40 par); Rm 12,14.21 (Cf. Mt 5,38-48 = Lc 6,27-36); Act 20,35 etc. 
cada uno de ellos era objeto de una enraizada fe común ${ }^{52}$. Como el Jesús histórico aseguró «estar en medio de» sus discípulos o en su comunidad mesiánica y efectivamente con ellos estuvo desde el principio hasta el fin de su ministerio ${ }^{53}$, así el Cristo resucitado vive con la Iglesia postpascual o activamente está con ella. Lo que significa: El Resucitado se identifica fundamentalmente con el Jesús histórico, cuya Comunidad mesiánica se prolonga sustancialmente en la Iglesia postpascual.

c) Añadamos que la actualidad de este mensaje anastasiológico es evidente. Bajo muchos aspectos. Ya la primordial misión evangelizadora de la Iglesia primitiva es sin duda paradigma o modelo de la Iglesia hodierna. Exhortada por su Magisterio conciliar y papal a la evangelización y «neoevangelización» universal, como absoluto quehacer primario de su misión en el mundo ${ }^{54}$, todos los miembros de «la Católica» (San Agustín) y toda comunidad eclesial -diócesis, parroquia y comunidades de vida consagrada- debe hoy tomar conciencia de ello: ${ }_{¡}$ Renunciar o trascurar esa tarea del todo primordial sería un gravísimo pecado contra el primer precepto -«iid!»- del Resucitado, una verdadera apostasía eclesial de sus discípulos o enviados como miembros de «la Católica». Por lo demás, la evangelización de la Iglesia no consiste en esa simple instrucción religiosa, que solamente logra creyentes en el vago Ser supremo o, a lo sumo, seguidores de un «recortado» Cristo liberal o escatológico, pedagógico humanista o taumatúrgico benefactor de los hombres; la evangelizadora misión de la Iglesia -de toda auténtica comunidad cristiana- consiste más bien en «hacer discípulos» de Jesús o en lograr verdaderos creyentes del Resucitado triunfador de la muerte, partícipes de su Resurrección porque, bautismalmente «resucitados con Cristo» a «una nueva vida» anastásica o «incorporados a la vida» de la «Trinidad santa ${ }^{55}$. ¡Solo éstos -no los simplemente religiosos - pueden cumplir la evangelizadora misión de «salar la tierra» de los incrédulos e «iluminar el mundo» de los meros creyentes y «fermentar la masa» humana de paganos o neopaganas ${ }^{56}$, con el experimentado testimonio sobre el eterno y personal «Amor más fuerte que la muerte» presencializado en el «unigénito Hijo de Dios», venido «al mundo» pecador para «morir por nuestros pecados y resucitar para nues-

53. Lc 22,27b; Cf Mc 1,16-20par. 29-31par; 2,15-17par; 3,14; 4,10-12par; 6,30-31par. 4850par; 7,17ss (=Mc 15,12ss); 8,27-30par; 9,30-37par; 10,32-45par; 13,1-14.50par; Mt 5-7par; 13,36ss; 25,1-45; Lc 8,1-3; 11,1-13; 17,1-10; 18,1-8.15-17par; Jn 2,1-4; 4,31-38; 9,1-3; 11,7-16; 13-17.

54. Cf. Conc. VAT. II, Const. LG, II, 9.17; Const GS, IV, 40-42; Decr. AG, 1,5; IV,23-24; PABlo VI, Exh.apost EN,I,14-16; JuAN PABlo II, Exh.apost. CT,I,15; III, 18-19; ID., Exh.apost. ChL,Intr. 4; III, 33-36.44.

55. Cf. Rm 6,4; Ef 2,5-6; Col 2,12; 3,1-4; Mt 28,19b.

56. Mt 5,13-16; 13,33 = Lc 13,20s. 
tra justificación»! ${ }^{57}$. ¡Sólo esos verdaderos o anastasizados «discípulos» de Jesús -no los meros creyentes- han vencido el esclavizante «miedo a la muerte» ${ }^{58} \mathrm{y}$, fortificados con «el Espíritu» del Resucitado, son capaces de ofrecer a los hombres de «todas las naciones paganas» o neopaganas el esperanzador «testimonio de la «victoria» de Jesús sobre «la muerte» suya y nuestra! ${ }^{59}$. La Iglesia hodierna sólo puede cumplir su católica misión evangelizadora, mediante esos verdaderos «discípulos» del Resucitado o cristianos adultos en la fe pascual. Lo que exige naturalmente de aquélla «enseñarles a observar todo cuanto preceptuó» Jesús ${ }^{60}$ : Fortificar su fe, mediante una catequética formación ${ }^{61}$ permanente ${ }^{62}$ y progresiva, «orgánica y sistemática» ${ }^{63}$, hodiernizada o debidamente adaptada al pensamiento, lenguaje y cultura del hombre actual ${ }^{64}$, siendo asimismo «integral» o transmisora de toda la fe y moral cristiana ${ }^{65}$ contenida en «el creo» ${ }^{66}$ y en el «Sermón de la Montaña» ${ }^{67}$ respectivamente, no sin centrarse en «el misterio de Cristo» ${ }^{68}$ o el Hijo de Dios «por nosotros» encarnado, muerto y resucitado. Quien -iy esto es en extremo consolador para todo cristiano! - ha decidido «estar con nosotros» o asistir eficazmente «todos los días» a su Iglesia evangelizadora, «hasta el fin» de su salvífica misión existencial en la tierra o en la historia humana.

\section{B. Una tradición histórica}

Añadamos seguidamente, que la detectada tradición anastasiofánica de Mt (Cf. supra) no es creación literaria de la Comunidad cristiana, traslucien-

57. Cant 8,6-7; Jn 3,13-17; Gal 4,4-5; Rm 4,25.

58. Hebr 2,14-15; Cf. Seudo-Bernabé, Epist. 16,9; San Justino M., 1 Apol. 57,2 («ino tememos la muerte!»); 2 Apol. 10,8; Minucio FÉlix, Octavius 8; TERTUliano, De testimonio animae, II 5; IV 7.9; San Hilario, De Trin., I 14; x 12; San Agustin, De mor. Eccl.Cath., I 22,40; De Civ.Dei, I 11; XIII 4; In.Ioan.Ev.Tract. 43,12. A este respecto, Cf. S. SABUGAL, Liberación y secularización, Barcelona 1978, 249-66;:21ss (fuentes + bibliogr.); Credo 1117-20 (fuentes + bibliogr.).

59. Cf. Lc 24,46-49; Act 1,8; 1 Cor 15,20-23.45.51-57; 1Tes 4,13-17.

60. Mt 28,20a; Cf. supra, n.51.

61. Cf. JUAN PABLO II, Exh.apost. CT, I 14-IX 71.

62. Cf. ID., o.c., III 20.

63. ID., o.c., III 21.22 .

64. Cf. ID., o.c., II 17; IV 31; VII 53; VIII 59.

65. Cf. ID., o.c., IV 27.29-30.

66. Cf. ID., o.c, IV 28. A este respecto, Cf. S. SABugal, Credo. La fe de la Iglesia, Zamora 1985, 38-46 (trad. ital., Roma 1990, 40-49).

67. Cf. S. SABugal, Abbá. La oración del Señor, Madrid 1985, 153-62. 670-90 (bibliogr.).

68. JUAN PABLo II, o.c., III 20. 
do por e contrario aquella tradición varios indicios objetivos de su historicidad sustancial ${ }^{69}$. En efecto:

a) Aquella tradición contrasta con muchos datos característicos de las prístinas tradiciones anastasiológicas y anastasiofánicas de la Comunidad primitiva. El total silencio de «Pedro» (o «Simón» y «Cefas») en esta tradición contrasta visiblemente con su relevante mención en el contexto de prístinas confesiones pascuales y su puesto de relieve en el primer kérygma anastasiológico (Act 2-10) de la Iglesia primitiva ${ }^{70}$. Cuyo característico uso anastasiológico de argumentos bíblicos así como de títulos y confesiones cristológicas, de reflexión teológica sobre la eficacia de la Resurrección y sobre la modalidad corporal del Resucitado ${ }^{71}$. así como el empleo del verbo «manifestarse» ${ }^{72}$ está del todo ausente en esa tradición anastasiofánica; el cual testimonio sobre el «bautismo» conferido «en el nombre de» las tres divinas Personas (v. 19b) -único en el NT-, no sintoniza del todo con el reiterado testimonio sobre el «bautismo» administrado «en el nombre del Señor Jesús» ${ }^{73}$. Por lo demás, si algunas frases de esa tradición son únicas en el NT ${ }^{74}$, otros de sus vocablos y expresiones son ignorados por los neotestamentarios escritos extraevangélicos ${ }^{75}$. Entre ellos figuran el pasivo divino «me fue dada» (=edóthe) y la expresión «todas las naciones» (=pánta ta éthne) o pueblos (vv.18b.19a.): Clara evocación de la profecía daniélica sobre «el Hijo del hombre» mesiánico, «a quien fue dada (-edóthe) potestad», para que «todas las naciones (pánta ta éthne) le den culto» ${ }^{76}$. Ahora bien, la cristología del «Hijo del hombre» no es característica ni relevante en los escritos pre-evangé-

69. A este respecto, Cf.: J. SCHMID, Das Evangelium nach Matthäus, Regensburg ${ }^{5} 1965$, 392-97 (trad. españ., Barcelona 1967, 563-57); E. LOHMEYER-W. sCHMAUCH, Matthäus 414-26 (passim); J. KREMER, Osterevanglien 91; J. GNILKA, Matthäus II 511.

70. Lc 24,34; 1Cor 15,5a. Sobre la tradición histórica de los primeros kérymas de Pedro (Act 2-5.10) remitimos a nuestro análisis histórico-tradicional de esos relatos (Cf. EstAg 35 [1990], 1-14.200-13; 27 [1992], 253-71.), tras el que emerge el relevante puesto de Pedro en la Iglesia primitiva, confirmado por el «lugar importante» de aquél «para Pablo»: K. P. DoNFRIEDJ. A. Fitzmyer, Pedro en las epístolas paulinas: «Pedro en el NT, Santander 1976, 31-44:31; Cf. R PESCH, Képhas: EWNT II 721-232:722s; ID., Pétros: Ib., III 199.

71. Cf. Rm 4,25; 1 Cor 15,$4 ; 1$ Tes 1,$10 ; 4,14$.

72. Ophthe: Lc 24,34 ; 1 Cor 15,5-8.

73. Cf. supra, n. 47 (textos).

74. Así «enseñándoles» y «estoy con vosotros» (v.20a.b: Cf. supra, n.. 21.26). Así como el pasivo divino, «me fue dada» (v.18b) en referncia a Jesús: Cf. supra, n.10 (jninguno de esos textos se refiere a El!

75. Si el verbo «matheteúein» (v.19a) sólo figura en Act 14,21 (Cf. supra, n.14), «todas las naciones» (v.19a) y «todo cuanto» (v.20b) no figuran en los escritos extraevangélicos del NT: Cf. supra, nn. 15.22 .

76. Dan 7,14 (LXX). Este influjo daniélico en los mencionados textos de la redacción y tradición mateana es subrayado con razón por los autores: E. LOHMEYER - W. SCHMAUCH 417; J. 
licos del NT, como lo muestra ya la total ausencia de aquel título en las Ep. paulinas y católicas así como en las confesiones e himnos cristológicos de la Comunidad primitiva ${ }^{77}$. Es pues claro: La postpascual Comunidad cristiana no pudo crear esa tradición anastasiofánica, varios de cuyos vocablos y expresiones le son del todo extraños y, por lo demás, toda ella contrastante con esenciales datos característicos tanto de su fe y confesión cristológica como de su praxis bautismal.

b) Por otra parte, se trata de una tradición sintonizante fundamentalmente con el modo de hablar o lenguaje característico de Jesús ${ }^{78}$, así como con su lengua materna o el arameo galilaico ${ }^{79} \mathrm{y}$ con ideas o concepciones distintivas de su mensaje salvador ${ }^{80}$. En efecto:

Características del modo de hablar propio de Jesús son ya las expresiones enfáticas «me fue dada» $\mathrm{y}$ «he aquí» que «yo estoy» (vv. 18.20), reflejando todas ellas el «soberano yo» divino así como la «sostenida solemnidad y majestuosa nobleza» de su «lenguaje» ${ }^{81}$; al que también el uso del pasivo divino -«me fue dada» (v.18a)- caracteriza ${ }^{82}$. Y así tanto el imperativo «haced discípulos» (v.19a) como la exigencia de «observar todo cuanto os man-

DUfour, Résurrection 140 (trad. españ., 153); J. P. MEIER, Law and history in Matthew's Gospel (AB71), Rom 1976,36s; ID., a.c., 413s.

77. Así con R. H. Fuller, The foundations of NT christology, London 1965, 144-51.20327.229 (trad.españ., Madrid 1979, 149-58.212-42.245), Cf. también: O. Cullmann, Christologie du NT, Neuchâtel-Paris 1958, 143-56; F. HANN, Christologische Hoheitstitel (FRLANT 83), Göttingen ${ }^{3}$ 1966,38; ID., Huiós: EWNT III 927-35:934s; C. ColPE, Der Menschensohn im NT: ThWNT VIII 433-74:465-68.

78. Cf. H. Schurmann, Die sprache des Christius: BZ 2(1858) 54-84; J. Jeremias, Neutestamentliche Theologie, Gütersloh 1971,19-45: trad. españ., Salamanca 1974, 21-52 (bibliogra.).

79. Cf. G. Dalman, Jesus-Jeschua, Leipzig 1922 (repr. Darmstadt 1967), 6-15; ID., Die Worte Jesu, Leipzig 1930 (repr.Darmstadt 1965), 1-10; M. BLACK, An aramaic approach to the Gospels and Acts, Oxford 3 1967,41-49:48s; J. JerEMIAS, Theologie 14-19:trad.españ, 15-21 (bibliogrs.); S. SABUGAL, Abbá 317-23:321ss (bibliogr.). Este arameo galilaico o lengua materna de Jesús está representado sobre todo por el «Targum palestinense al Pentateuco» (=«Nephyti I») descubierto y publicado por el español A. Diez MaCho (Cf. S. SABugaL, $A b b a ́, 321$ s, n.27), usado por nosotros con la sigla $T g P I$.

80. Citamos solamente: G. Dalman, Worte 73-280; E. PerCy, Die Botschaft Jesu, Lund 1953, 19-307; T. W. MANSON, The teaching of Jesus, Cambridge 1963, 87-319; J. JEREMIAS, Abbá, Göttingen 1966, 17-229 (trad. españ., Salamanca 1981, 17-151.215-75); ID., Theologie, 62-284 (trad. españ., 74-346). N. PERRIN, Rediscovering the teaching of Jesus, London 1967, 54-206; S. SABUGAL, Abbá 366-723.

81. H. SCHÜRMANN, a.c., 58.62. Esto mismo expresa la veterotestamentaria y judaica orden divina de «observar todo cuanto os mandé» (v.20a) así como la veterotestamentaria y judaica promesa divina «yo estaré con vosotros» (v.20b), en las que el «Jesús» resucitado se pone eń lugar de Dios: Cf. infra, nn.101.103. 24:27).

82. Cf. G. Dalman, o.c., 183; J. Jeremias, Theologie 20-24:20-22.24 (trad.españ., 21-27:21- 
dé» (v.20a) refleja bien el «imperiosamente exigente» lenguaje de Jesús ${ }^{83}$, en la «total potestad» con que «envía» a sus discípulos (vv. 18b-19a) «habla uno, que... tiene poder» y cuyo «lenguaje» se distingue por «una especial determinación y potestad» ${ }^{84}$. Finalmente, la actualización de la profecía danielica en Jesús - «me fue dada toda potestad»- y en la misión universal - «todas las naciones»- de sus discípulos (vv. 18b-19a) ${ }^{85}$, sintoniza bien tanto con la «actualidad escatológica» propia de su lenguaje ${ }^{86}$ como con su reiterada -explícita o implícita- referencia a la mencionada profecía daniélica ${ }^{87}$.

A ello se suman los numerosos semitismos aramaicos de esa tradición anastasiofánica. Eso refleja ya la reiterada construcción paratáctica del relato, cuyo probable «influjo» aramaico se debe a que aquélla es «mucho más frecuente en arameo que en griego» ${ }^{88}$. También el uso del participio presente -“yendo» y «bautizando» (v.19) así como «enseñando» (v.20)- es «una característica especial del arameo» ${ }^{89}$. Por lo demás, «fueron al lugar, que les preceptuó» o dijo Jesús (v.16) es una frase usada tanto por el AT hebreo como por el antiguo Targum palestinense al Pentateuco (=«Neophyti I») ${ }^{90}, \mathrm{y}$ cuyo origen aramaico es por tanto probable ${ }^{91}$. Lo es sin duda «les habló diciendo» (v.18a) ${ }^{92}$, y el pasivo divino «me fue dada» así como la construcción «en cielo y sobre la tierra» (v.18b) ${ }^{93}$. Semitismos aramaicos son asimismo: La construcción «yendo» + verbo ${ }^{94}$, el verbo «hacer discípulos» ${ }^{95}$ y la

85. Dan 7,14:Cf. supra, n. 75.

86. H. SCHÜRMANN, a.c., 73-74:73.

87. Cf. H. SCHÜRMANN, a.c., 59s; infra, n. 17 (bibliogr.).

88. M. BLACK, o.c., 61-69:61.

89. M. BLACK, o.c., 130.

90. Cf. TgPIGén 13,3; 22,3.9; TgPIEx 32,34; TgPIDt 9,7; 11,5; 12,5.14; 16,16; 18,6: Los Once «ozélû» I'aterá' deamár lehôn» Jesús.

91. Sobre el frecuente uso del nombre «Yešúa ${ }^{\circledR} »$ por el antiguo Judaismo palestinense, Cf. W. FOERSTER, ThWNT, III 283-87. Esta sería, pues, la retraducción aramea del v. 16: «Had esaryyá' ozélû l'aterá' deamár, léhôn Yešúa ${ }^{c}$. La del v.17 -«y lo vieron»- no es difícil (Cf. TgDt 4,9; 27,1): «Uehammunóhî».

92. Hebraísmo y a arameísmo (Cf. M.-J. LAGRANGE, Matthieu LXXXIX; contra G. DALMAN, o.c., 20): Cf. TgPIGén, 17,3; 23,8; 34,8 etc; TgPIÉx 6,12.29; 14,1; 25,1 etc; TgPIDt 1,6; 2,17; 13,$3 ; 27,9 ; 32,48$ etc: «Uemalél Yešúa ${ }^{e}$ immehón lememár».

93. Si el uso del pasivo divino es un frecuente semitismo aramaico (Cf. G. DALMAN, Worte 183-85; J. JEREMIAS, Theologie 22s: trad. españ., 24s), el paralelismo semítico entre «me fue dada» y Dan 7,14a («le fue dada») es evidente (Cf. supra, n. 76). Su correspondiente arameo sería: «Yeháb lî kôl śultán». Por lo demás, el paralelismo de la construcción «en cielo y sobre tierra» con la tradición judeo-cristiana de Mt 6,10 (Cf. supra, n. 12) muestra que su origen aramaica es muy probable (Cf. S. SABugAL, Abbá 254: fuentes aramaicas + bibliogr.), siendo su correspondiente arameo: «Bišmayá'».

94. Frecuente en labios de Jesús: Cf. G. DALman, o.c., 16s; M. BLACK, o.c., 64-65.125.

95. Este verbo puede ser un semitismo hebraico (=«lamád») o aramaico (=«laméd»), que en su forma intensiva (=«piel») significa «enseñar» o «instruir» (Cf. M. JASTRow, Dictionary 
designación «todos los pueblos» (v.19a) ${ }^{96}$, el imperativo bautizándoles» ${ }^{97} \mathrm{y}$ la construcción «en el nombre» (v.19b) ${ }^{98}$. Pueden ser también arameismos: «Enseñándoles ${ }^{99}$ a observar ${ }^{100} \mathrm{y}$ «todo cuanto os mandé» (v.20a) ${ }^{101}$. Semitismos arameos son finalmente tanto la partícula demostrativa «y he aquí» ${ }^{102}$

712:ad voc.), muy usado por el antiguo Judaísmo rabbínico en la «enseñanza» de la Torah (Cf. R. H. RENGSTORF, Mantháno: ThWNT IV 403-6). La retraducción aramaica de «yendo, pues, haced discípulos» (v.19a) sería: «'azîlu ulemôdehûn».

96. Traduce así sin duda la frecuente y antigua expresión aramaica «kôl 'ummayá'» $T g P I$ Gén 22,18; 26,4; TgPIÉx 19,5; TgPIDt 7,6.7.14; 10,15; 11,23; 28,10.64; 29,23.

97. Si el uso del imperativo presente es un arameísmo (Cf. supra, n. 89), en arameo se usaba la forma activa (=«afel») del verbo «tebál» (=sumergir:Cf. M. JASTRow, Dictionary 517, ad voc.) para designar el bautismo judaico de los «prosélitos» (Cf. STR. -BILL., I 102s; A. OEPKE, Bápto: ThWNT I 532s): «Bautizándoles» (v.19a) 'matbêlhón (aram.).

98. »Lehaššem»: Cf. STR. -BILL., I 590-91. 1054s; M. Jastrow, Dictionary 1590. Los nombres de las tres divinas Personas serían, pues, en arameo: «Ha'abbá' uehabberá' ueharûa qudšsá».

99. Si los cuatro Evangelistas atestiguan el uso de «didáskein autóus» en labios de Jesús (Cf. supra, n. 21) y el part. presente «enseñando» es un arameísmo(supra, n. 89), «enseñándoles» equivale a la forma intensiva del verbo arameo «laméd» (Cf. supra, n. 12; K. H. RENGSTORF Didásko: ThWNT II 140s. «Enseñándoles»=aram. «melammedhôn») o más probablemente, «yeléph» (Cf. M. JASTROW, Dictionary 579), preferido efectivamente éste último por el antiguo Targum palestinense al Pentateuco (=«Neophyti I»): Cf. TgPIDt 4,10.14; 6,1; 11,19; 20,18; $31,19$. 22. «Enseñándoles» =aram. «mellephhôn.

100. Verbo característico del lenguaje de Jesús (Cf. supra, n. 83), correspondiente al aramaico «šemár» (=«observar» los preceptos de la Torah: Cf. M. JASTROW, Dictionary 1600; H. RiESENFELD, Teréin ThWNT VII 140s) o, más probablemente, al verbo aramaico «netár» (=observar» los preceptos de Dios, la Ley etc: Cf. M. JASTROW, Dictionary 901; de otro modo E. LOHMEYER-W.SCHMAUCH 421,n.10, preferido en efecto este último por el antiguo Targum palestinense al Pentateuco (=«Neophyti I»): Cf. TgPIGén 2,15; 3,15.24; 27,40; TgPIÉx 13,10; 19,5; TgPILev 26,3; PgPIDt 4,2.40; 5,26; 6,17; 7,9.11; 8,1.2.6.11; 10,13; 11,8; 13,5; 17,19; 26,18; 27,$1 ; 28,15.45 ; 30,10.16$.

101. : Frase frecuente en el AT hebreo y en el Judaico Targum palestinense (=«Neophyti I»), para expresar la orden de Dios, a un individuo o a todo Israel, de hacer u observar «todo cuanto os mandé» (Dt 12,11): «eth kôl-ašer anokí metzauéh ethkém»; TgPIDt 12,11: «kôl mah dî 'anáh mephaqqéd yathkôn»): Cf. TgPIÉx 7,2; 25,22; 34,11.32; 40,16; TgPINúm 30,1; TgPIDt $3,1.41 ; 12,11.14 ; 30,2$. Por lo demás, si la construcción «todo cuanto» y el verbo «mandar»son usados por los cuatro Evangelistas en labios de Jesús (Cf. supra, n. 22.23), como características de su lenguaje (Cf. supra, n. 83), «todo cuanto» es un semitismo hebreo (=«kôl-ašer») o arameo (=«kôl mah de»: Cf. TgPIGén 1,31;6,22;7,5.22;12,20;21,12; TgPIÉx 7,2;9,25; 18,1.8.14;19,8;24,7;40,16 etc; TgPILev 5,4;10,12 etc; TgPINúm 1,50;2,34;22,2 etc;TgPIDt 18,7 etc), reproduciendo el verbo «mandar» la dorma intensiva del respectivo arameo «pheqád» (Cf. M. JASTROW, Dictionary 1207). ¡Usando aquella exigencia divina (Cf. supra), el «Jesús» resucitado se pone en lugar de Dios!.

102. Usada sin duda por Jesús, como lo atestiguan las fuentes evangélicas, para «llamar la atención» a su mensaje (Cf. supra, n. 25), es un semitismo hebreo (=«uehinnéh»:Gén 1,31; 22,13 etc; Ex 5,16; 7,16 etc; Lev 13,5; 14,3 etc; Núm 12,10; 23,11 etc; Dt 1,10; 9,13 etc. A este respecto, Cf. M. HohAnnessohn, Der Wahrnehmungssatz bei den Verben des Sehens in der hebräischen und griechischen Bibel: $\mathrm{Kz}(60$ (1940) 30ss; I. LANDE Formelhafte Wendungen der Umgangssprache im $A T$, Leiden 1949, 15-16.36ss). y arameo (=«uehá'» o «uehá'»: H. SCHÜRmANN, a.c., 63, n. 57; M. JASTROw, Dictionary 327.328), frecuente éste (=«uehá'») en el antiguo Targum palesti- 
como la promesa del Resucitado: «Yo estoy con vosotros ${ }^{103}$ todos los días ${ }^{104}$, hasta el fin» (v.20b) ${ }^{105}$. No hay duda: Esa tradición anastasiofánica refleja por doquier el arameo galilaico, de modo que, sintetizando los precedentes análisis, podemos reconstruir su probable texto prístino:

«Los Once fueron al lugar, que les ordenó Jesús (v.16) y lo vieron (v.17). Y Jesús les habló, diciendo: Me fue dada toda potestad en cielo y sobre tierra (v.18); yendo pues haced discípulos a todas las naciones, bautizándolas en el nombre del Padre y del Hijo y del Espíritu Santo v.19). Y he aquí que yo estoy con vosotros todos los días, hasta el fin» (v.20).
«Had 'hesaryyá' ozélû l'aterá' deamár léhôn Yessúa' (v.16). Uehammunôhi (v.17). Uemalél Yessúá simmehôn lememár: Yeháb lî kôl sultán bismayá' uebeareá' (v.18); 'azîlû ûlemodehûn kôl 'ummayá', matbêlhôn l'hassem va $_{v}$ Abba' uehaBBerá' ueha Rûa Qûdssa'(v.19.). Uehá' 'aná' simmakôn kôl yommayá' 'ad sôphá'» (v.20).

Tal sería el original texto de esa tradición, en el arameo galilaico o la lengua materna de Jesús, normalmente usada por él en su enseñanza ${ }^{106}$. En ella, p.e., respondió Jesús al interrogante mesiánico de los discípulos de Juan Bautista ${ }^{107} \mathrm{y}$, hacia el ocaso de su ministerio público, en ella enseñó el Maestro a sus discípulos «el Padrenuestro» o su oración característica ${ }^{108}$. En el arameo galilaico o su lengua materna, pudo, pues, el «Jesús» resucitado hablar o instruir por última vez a «los Once» discípulos.

nense (=«Neophyti I»): Cf. TgPIGén 1,$31 ; 15,17 ; 22,13 ; 24,15 ; 28,12$ etc; TgPIÉx 5,16; 7,16 tc; TgPILev 13,5.6; 14,3 etc; TgPINúm 3,12; 12,10 etc; TgPIDt 1,10; 9,13; 17,4; $18,18$.

103. Expresión semítica y, como promesa de la existencia de Dios a un individuo o a todo el Pueblo, frecuente en el AT hebreo (Gén 21,22; 26,3;28,15; Ex 10,10; Dt 2,7;20,1 etc; Sal. 46,8; Is 8,$10 ; 40,10 ; 43,5$ etc) y en el arameo del antiguo Targum palestinense (=«uehá' 'aná' immakôn»: PgPIEx 10,10; TgPIDt 20,1; TgJces 2,13; TgPIGén 21,22; 26,3; 28,15; 39,2. 21.23; TgPIDt 1,30; 2,$7 ; 4,7$ etc.

104. Expresión rara en el griego neotestamentario (Cf. supra, n.27) y semítica probablemente: Usada con frecuencia en su estado absoluto por el AT hebreo (=«Kôl yemé») y por el aramaico Targum palestinense (=«kôl yômé»), menos frecuente en su estado absoluto (=hebr.: «kôl heyyamîn»; aram. «kôl yomayyá'»TgPIDt 4,40; 6,24; 33,12; TgJos 2,18 etc). Apropiándose esa promesa divina, «Jesús ocupa el lugar de Yahveh...»: J. GNILKA, Matthäus II 511.

105. Si tanto la conj. «hasta» como el sust. «el fin» fue usada ya por Dan 7,26 (=aram.) y, luego, alguna vez por Targumín antiguos (Cf. TgPIDt 11,12; TgonkGén 49,1), pudiendo por tanto haberla usado «Jesús» mismo (así con J. DALMAN, Worte 127). Más tardías son las expresiones análogas - “ad gitzá’» y «'ad ha'olám»- del Judaísmo rabínico: Cf. STR. -BILL., I 671; H. SASSE, Aión: ThWNT I 207.

106. Cf. J. JeREMIAS, Theologie 14-45: trad. españ., 15-52 (bibliogr.); S. SABugal, Abbá 322s (bibliogr.).

107. Mt. 11,5-6 = Lc 7,22-23: Cf. S. SABUGAL, La embajada mesiánica de Juan Bautista, Madrid 1980, 172s.

108. Mt 6,9-13 = Lc 11,2-4; Cf. S. SABugaL, Abbá 323-30.356-64 (bibliogr.). 
Pues, por lo demás, esa instrucción sintoniza con ideas o concepciones centrales de su mensaje. Entre ellas figura la autoconciencia, que Jesús tuvo de «haber sido entregado todo por el Padre...» o la plenitud de la revelación de sí mismo y, por tanto, la plenitud de todo poder ${ }^{109}$. Por lo demás, tanto su orden divina de «observar todo cuanto os mandé» como su divina promesa de «estar con vosotros» ${ }^{110}$ refleja bien la potestad de quien -Jesús con autoridad inaudita o divina habló y exigió ${ }^{111}$, haciéndolo en efecto "como si estuviera en lugar de Dios» ${ }^{112}$. Añadamos que el envío de los discípulos por el Resucitado a «todas las naciones» sintoniza perfectamente con el universalismo del mensaje salvífico de Jesús o de quien aseguró «ser designio divino la predicación de la Buena Noticia a todas las naciones» ${ }^{113}$. Por otra parte, el mandato de «bautizar» a los devenidos creyentes entre «todas las naciones», dado por el Resucitado a sus discípulos, se enraiza sin duda en la praxis bautismal de Jesús ${ }^{114}$, siendo por tanto el postpascual bautismo cristiano «la eflorescencia de un acto que tuvo lugar antes de Pascua» o más bien, «la prolongación del bautismo realizado y ordenado «por Jesús» ${ }^{115}$. No sólo eso. La tácita pero clara evocación de la profecía daniélica sobre el mesiánico «Hijo del hombre» (Dan 7,13s) en la «potestad total» otorgada por Dios al Resucitado así como el envío de sus discípulos a todas las naciones» ${ }^{116}$, prolonga el

109. Lc 10,22 = Mt 11,27; Cf. S. SABugal, Abbá 391 (bibliogr.).

110. Cf. supra, n..81.101.103.

111. Mc 2, 10par; 8,34-38par; 13,31 par; Mt 5,21-48; 7,24-27; 11,27 (=Lc 10,22). 32-33; Lc 15,1-32 etc: Cf. M. HenGEL, Nachfolge und Charisma (BZNW 34), Berlin 1969, 74-79; J. JEREMIAS, Theologie 239-43 (trad. españ., 323s); W. KASPER, Jesus der Christus, Mainz 1974, 119-22 (trad. españ., 125-27); S. SABUGAL, La embajada 154-55. 178.91.

112. . E. FuCHS, Zur Frage nach dem historischen Jesus: ZThK 53 (1956) 210-29:219; Cf. E. PERCY, o.c., (supra, n.80), 123-65:124; M. SMITH, Tannaic paralleles to the Gospel (JBL MS 6), Philadelphia (Pens.) 1968, 153-54.159; F. CHRIsT, Jesus sophia, Zürich 1970, 61-54; J. JEREMIAS, Theologie 65-67.198-201.239-43 (trad. españ. 77-80.240-44.291-96); X. LÉON-DUFOUR, o.c., 373 (trad. españ., 332); W. KASPER, o.c., 120 (trad. españ., 126); S. SABUGAL, La embajada 154.178.188.191.

113. Mc 13,10 (=Mt 21,14); Cf. 7,24-30 (=Mt 15,21-28); 10,45 (=Mt 20,28); 11,17; Mt 5,13-14; 8,11 (=Lc 13,29); 25,31-32; Lc 10,1-16; Jn 10,16 etc. A este respecto, Cf.: J. JEREMIAS, Jesu Verheissung für die Völker, Sttutgart ${ }^{2}$ 1959,40-62; ID., Theologie 235-37 (trad. españ., 286-88); X. LÉONDuFour, o.c, 420-22 (trad. españ., 369-71); S. SABUGAL, La embajada, 177.185-91. Sobre el universalismo del «reino» y «reinado de Dios» predicado por Jesús (Mc 4,30-32 par; Mt 6, 10a par; 13,24-30.47-50; 22,1-10 = Lc 14,15-24 etc), Cf. S. SABUGAL, Abbá 285-86.496-97.(bibliogr.) 526.

114. Jn 3,22.26; 4,1: Cf. S. SABugal, Abbá 415s (que Jesús bautizó es opinión de muchos autores modernos -CH. H. Dodd, X. LÉon-Dufour, R. SCHnNACKenburG, R. E. Brown, J. JeREMias, F. M. BRAUn, G. R. BEASLEY-MURRAY etc- y antiguos, ahí citados: 416, n.149.

115. X. LÉON-Dufour, «Et lá, Jésus baptisait» (Jn 3,22): «Mél. E. TisseranT» I (ST 231), Città del Vaticano 1964, 295-309:309; S. SAbugal, Abbá, 417; así también J. ScHMID, Matthäus 393 (trad. españ., 564); G. R. BEASLEY-MurRay, Baptism in the New Testament, London 1963, 83-92:92.

116. Esa evocación daniélica es subrayada por muchos autores: Cf. supra, n. 76; W. TRILLING, Das wahre Israel (StANT 10), München 1964, 21-33 (bibliogr.). 
no dudoso empleo del daniélico título «Hijo del hombre» por Jesús, para rechazar la nacioanalística y política concepción mesiánica del Judaismo contemporáneo y, a la vez, subrayar tanto la universalidad como el carácter regio y judicial de su propia dignidad mesiánica ${ }^{117}$. Finalmente, el envío de los discípulos por el Resucitado a «todas las naciones», para «hacerlas discípulos» y «bautizarlas» o introducirlas en el nuevo Pueblo de Dios, inaugura el preanunciado aflujo escatológico de «todas las naciones» $\mathrm{y}$ «pueblos» a «la casa de Dios» o a su nuevo Pueblo ${ }^{118}$, sintonizando aquel envío del Resucitado con la actualización de la salvación escatológica inaugurada con palabras y «signos mesiánicos -milagros y exorcismos- por Jesús ${ }^{119}$.

Sintetizando estos análisis histórico-tradicionales sobre la mateana Cristofanía a los «Once discípulos» (Mt 28,16-20), podemos decir: Tras la interpretación del relato por la redacción del Evangelista late una visión y sólida tradición judeo-cristiana de 'aquella Cristofanía; cuyo marcado contraste reiterado con datos característicos de las prístinas tradiciones anastasiológicas y anastasiofánicas de la Comunidad postpascual, así como su coherencia o sintonía tanto con el lenguaje característico y la lengua materna de Jesús como con ideas centrales de su mensaje, aseguran la historicidad sustancial de aquella tradición ${ }^{120}$.

SANTOS SABUGAL, OSA

Instituto Patrístico «Augustinianum»

Roma

117. G. DALMANn, Worte, 191-291;:206ss; J. JeREMIAS, Theologie 245-63:252-55.259ss (trad. Españ., 299-20:307-11. 316ss (bibliogr.); Cf. también: E. PERCY, o.c., 225-307:256-59; T. W. MANSON, o.c., 211-34: 227-32; W. KASPER, o.c., 126-28 (trad. españ., 132-34).

118. Is $2,2-4$ (=Miq 4,1-3); Cf. Is 11,$10 ; 12,4 ; 40,5 ; 42,6(=49,6) .10 .12 ; 51,4-5 ; 52,10 ; 60,3$; $61,9.11 ; 62,10 ; 66,12$ a.19; Zac. 2,7; 8,20-22 etc. Sobre el universalismo salvífico de los Profetas, Cf.: R. MARTIN-ACHARD Israël et les nations, Neuchâtel 1959, 39-48.55-66; G. E. WRIGHT, The nations in hebrew Prophecy: Encounter 26 (1965) 225-37; P. E. DION, Universalismo religioso en Israel, Estella 1976, 54-77; E. BEAUCHAMP, Salut:DBS XI 616-19:617s.

119. Cf. . PERCY, o.c., 178-234 (passim); X. LÉON-Dufour, o.c., 378-97 (trad. españ., 33450); J. JEREMIAS, Die Gleichnisse Jesu, Göttingen ${ }^{7}$ 1965,11-24 (trad. españ. 144-53); ID., Theologie, 89-101.105-10 (trad. españ., 107-21.126-32); N. PERRIN, o.c., 154-206:202ss; S. SABUGAL La embajada 176-97; ID., Abbá, 486-51.502-28 (bibliogr.); ID., Credo. La fe de la Iglesia. Zamora 1986, 733s (trad. ital., Roma 1990, 799).

120. Contra J. LANGE, Erscheinen 470. Un «núcleo histórico» o un «recuerdo» real del Evento admiten: J. Kremer, Osterevangelien 91; J. GnILKA, Matthäus II 511; Cf. también J. SCHMID, Matthäus 392-97 (trad. españ. 363-70). 